INFORMAL HIERARCHY STRENGTH CHANGES

\title{
Informal Hierarchy Strength Changes and Their Effect on Performance
}

\author{
Karoline Evans* \\ Manning School of Business \\ University of Massachusetts Lowell \\ Lowell, MA 01854 \\ Bret Sanner* \\ LaPenta School of Business \\ Iona College \\ New Rochelle, NY 10801 \\ bsanner@iona.edu
}

*Both authors contributed equally in the preparation of this manuscript.

\begin{abstract}
Author Note
Correspondence concerning this article should be addressed to Karoline Evans, Manning School of Business, University of Massachusetts Lowell; 1 University Ave, Lowell, MA 01854; Phone: (978) 934-5528; email: karoline_evans@uml.edu
\end{abstract}

\section{Acknowledgments}

We would like to acknowledge the help that others provided. Andrew P. Knight made this project possible. Stuart Bunderson, Eileen Chou, Elana Feldman, Stephen Humphrey, Deanna Kennedy, and three anonymous reviewers provided valuable input into the preparation of this manuscript. 


\title{
Informal Hierarchy Strength Changes and Their Effect on Performance
}

\author{
Abstract \\ Despite qualitative evidence suggesting that changes in informal hierarchy strength likely impact \\ performance, informal hierarchy strength changes have received little theoretical or empirical \\ attention. We address this by extending structural adaptation theory (SAT) to develop and test a \\ theoretical model of why informal hierarchy strength changes and how those changes impact \\ performance. Building on SAT's principle that teams can become more ordered following \\ stimulation, we propose that pressure subsequently increases informal hierarchy strength. In \\ project teams where pressure starts low and increases at the midpoint, informal hierarchy should \\ weaken early in project life and strengthen after the midpoint. We also extend SAT's asymmetric \\ adaptability principle to consider not just the direction but also the rate of the changes. We \\ hypothesize that sharply strengthening informal hierarchy harms performance, but informal \\ hierarchy strengthening gradually improves performance. SAT also implies that gradual change \\ is promoted by inclusive discussions. Because most influential extraverts tend to squelch \\ inclusive discussions where most influential neurotics tend to be inclusive, teams with most \\ influential extraverts strengthen their informal hierarchy quickly where teams with most \\ influential neurotics strengthen their informal hierarchy gradually. We find support for our \\ theoretical model using longitudinal data and client performance ratings on self-managed project \\ teams. Our results contribute to SAT by showing its application to informal, unplanned changes \\ and introducing the rate of change to its asymmetric adaptability principle. Our findings also \\ highlight the importance of shifting informal hierarchy strength research away from the \\ predominant static approach and towards studying informal hierarchy strength changes. \\ Keywords: informal hierarchy, team dynamics, structural adaptation theory, personality, pressure
}




\section{Informal Hierarchy Strength Changes and Their Effect on Performance}

Teams are complex and dynamic systems (Arrow et al., 2004) that consist of members who must work interdependently to coordinate activities and knowledge (Humphrey \& Aime, 2014). One way that teams coordinate is through agreement on a shared course of action which, at times, involves a member deferring to another's recommendation (Anderson et al., 2012). As such, the pattern of "how a group, as a whole, is characterized by its members' dyadic influence and deference relations"-informal hierarchy strength — is an important part of most teams (Oedzes et al., 2019, p. 311; Kilduff \& Lee, 2020; Park et al., 2020). Indeed, informal hierarchies have been found in groups as varied as preschool children (Strayer \& Strayer, 1976) and top management teams (He \& Huang, 2011). Informal hierarchies are so pervasive that even when teams do not have a formal leader or formal hierarchy, they still rely on strong informal hierarchies (Oedzes et al., 2019). Moreover, informal hierarchy strength can affect important team outcomes and processes including creativity, coordination, conflict, satisfaction, and performance (for a review, see Bunderson \& Van der Vegt, 2018).

Teams also vary in their informal hierarchy strength. A team has a weak informal hierarchy when most of its dyads include two members who similarly defer to one another. In contrast, a team has a strong informal hierarchy when most of its dyads include one member who usually defers to the other member. Importantly, informal hierarchy strength changes over time. Indeed, qualitative research shows that informal hierarchy strength changes - changes in the proportion of a team's dyads that consist of one member who usually defers to the other member-occur in adolescents (Martin, 2009), nomads (Fein, 2012), surgical teams (Klein et al., 2006), and design teams (Bunderson \& Sanner, 2020). When informal hierarchy becomes stronger, the proportion of a team's dyads where one member usually defers to the other member increases. And when 
informal hierarchy becomes weaker, the proportion of dyads where one member usually defers to the other member decreases. Figure 1 depicts informal hierarchy strength changes.

---- Insert Figure 1 about here ----

Outside of documenting that unplanned informal hierarchy strength changes are a pervasive part of team life (e.g., Bunderson \& Sanner, 2020), research has uncovered little about these changes. This is problematic for at least two reasons. First, it means that informal hierarchy research neglects "the long-acknowledged notion that teams undergo significant changes over the course of their life cycle (Marks et al., 2001)" (Park et al., 2020, p. 1014). These changes may be especially significant for informal hierarchy strength, because unplanned changes over the course of teams' lifecycle have been shown to impact the extent to which members defer to one another (Anderson et al., 2012; Klein et al., 2006), which would lead to informal hierarchy strength changes. Second, though most researchers suggest that unplanned changes in informal hierarchy strength impact performance, there is considerable debate over how they impact performance. Some argue that changes in informal hierarchy strength can help teams align deference patterns with their dynamic environment (e.g., Klein et al., 2006) while others argue that they can distract from task completion (e.g., Moon et al., 2004). Therefore, research should investigate informal hierarchy strength changes to reflect the reality that teams undergo unplanned changes and that those changes have important performance implications.

Accordingly, we investigate why informal hierarchy changes occur and how those changes affect performance by extending structural adaptation theory (SAT: Moon et al., 2004). SAT is well-suited for bringing theoretical coherence to research on informal hierarchy strength changes. By viewing teams as networks that require energy to be ordered, such as having a strong informal hierarchy, SAT has implications for why informal hierarchy strength changes 
occur and how those changes affect performance. SAT is also one of the few empirically supported theories (Hollenbeck et al., 2011; Johnson et al., 2013) that predicts not only why changes may occur but in what ways. However, SAT studies primarily focus on planned, formal changes. Therefore, we extend SAT by developing a theoretical model that also encompasses unplanned, informal changes and their effect on team performance.

More specifically, we apply SAT in the context of self-managed project teams, teams that are formed without a formally designated leader to "create a novel product (themselves) by a deadline" (Gersick, 1994, p. 10). Self-managed project teams are increasingly popular (e.g., Scott et al., 2018) because they help organizations adapt in dynamic environments (Ilgen et al., 2005; Oh, 2012). Grounding our theory in self-managed project teams also allows us to overcome two of the primary barriers to developing and testing theories of unplanned changes: predicting timing and reducing confounds from formal leaders (McGrath, 1997). Because project teams undergo predictable shifts in pressure (Gersick, 1989, 1994), they are well-suited for predicting when and how informal hierarchy strength will change over time. Additionally, selfmanaged project teams do not have a formal leader who could create endogeneity issues by affecting informal hierarchy strength through actions such as changing members (e.g., Oedzes et al., 2019).

Consistently, we extend SAT to develop a theoretical model that we test on 3-waves of longitudinal data from 234 members on 55 self-managed student project teams. By extending SAT to investigate informal hierarchy strength changes, we make multiple contributions to the SAT and the informal hierarchy strength literatures. First, we extend SAT to increase its applicability for unplanned changes. To date, SAT has been limited to formal changes such as formally appointing a centralized leader (Hollenbeck et al., 2011) or changing task distribution 
(Moon et al., 2004). Therefore, by adding the important differences between unplanned, informal changes and planned, formal changes into SAT, we increase its explanatory power.

In so doing, we find a key distinction in SAT's asymmetric adaptability principle, which suggests that the strengthening of informal hierarchy is more problematic than the weakening of informal hierarchy. Where prior SAT examinations focus solely on the direction of the change, we show that the rate of change also matters. More specifically, we demonstrate that strengthening informal hierarchy gradually can improve performance, but strengthening informal hierarchy rapidly harms performance. Because informal changes vary more in the rate of change than formal changes (Boumgarden et al., 2012), this further underscores the importance of delineating between informal and formal changes in SAT, and of including the rate of change.

We also highlight the importance of informal hierarchy research devoting more attention to informal hierarchy changes by showing that they impact performance. This finding is a stark contrast with the predominantly static approach to informal hierarchy strength research, which finds an inconsequential relationship with performance on average (for a meta-analysis, see Greer et al., 2018). We also help to resolve the debate over whether informal hierarchy strength should be conceptualized as dynamic or static (for a review, see Bendersky \& Pai, 2018) by empirically showing that informal hierarchy undergoes unplanned changes. These findings not only respond to calls for research to take a dynamic approach when investigating team deference patterns (Humphrey \& Aime, 2014; Kilduff \& Lee, 2020; Park et al., 2020), but also suggest that informal hierarchy strength research should shift away from its predominantly static approach and towards studying informal hierarchy strength changes.

\section{Theory and Hypotheses}

\section{Structural Adaptation Theory (SAT)}


Similar to the goal of this paper, SAT was developed to help move teams research towards studying "within-group changes" over multiple periods of time and away from the predominant “static, between-group research designs" (Moon et al., 2004, pp. 681-682). Indeed, when SAT was created, there was so little research on team changes that its researchers based SAT off of the second law of thermodynamics and viewed teams as a network of members who must expend energy to stay connected (Johnson et al., 2006; Moon et al., 2004). More specifically, SAT conceptualizes teams as networks that vary in the extent to which they are ordered (Moon et al., 2004). An ordered network means that the power or deference relations between members are predictable at that point in time, such as certain members usually deferring to other members. In contrast, unordered networks have less predictable power or deference relations, such as equal deference between members making it difficult to predict who will defer to whom at a moment in time.

This focus on the extent to which a network is ordered makes SAT well-suited for studying informal hierarchy strength changes. Strengthening or weakening informal hierarchy aligns with increasing or decreasing the extent to which a network is ordered. As an informal hierarchy becomes stronger, the network becomes more ordered as deference between members predictably goes one-way. In contrast, when a team's informal hierarchy becomes weaker, more dyads have symmetric deference, which can create inconsistent deference patterns (Hage, 1995; Krackhardt, 1994). Because informal hierarchy strength represents a form of ordered network, SAT can be applied to informal hierarchy strength changes.

The two main principles of SAT build on the idea that more ordered networks require more energy to maintain or create. First, SAT proposes that there is a tendency for networks to become less ordered over time (Moon et al., 2004). Highly ordered networks take more energy and effort 
to maintain as members must work to sustain consistent deference relations. As a result, teams are likely to drift towards less effortful, less ordered networks unless an intervention energizes them to do otherwise (Beersma et al., 2009). Consistently, prior research has shown that formal interventions such as changes in reward systems (e.g., Baer et al., 2010; Summers et al., 2012) prompt networks to become more ordered.

Second, SAT proposes that networks have asymmetric adaptability-change from an unordered to an ordered network is more difficult than change in the opposite direction (Johnson et al., 2006; Moon et al., 2004). In particular, SAT research has shown that moving to more ordered networks harms performance, because team members who previously had shared authority must use time and energy to adjust to more restrictive networks (Hollenbeck et al., 2011; Johnson et al., 2013; Moon et al., 2004). Because network changes are difficult to coordinate, SAT has shown that inclusive discussions can help members to understand the necessity of change and subsequently do it in a more productive way (Johnson et al., 2013).

Despite SAT receiving strong empirical support and elucidating meaningful within-team changes, it has only been applied in a limited number of empirical studies. We believe this is because SAT research has predominantly focused on formalized, planned interventions in laboratory settings thereby constraining the phenomena researchers study using SAT. For example, Moon et al. (2004) finds that changes to different types of formal departmentalization are more problematic than others in a decision-making simulation; using the same simulation, Hollenbeck et al. (2011) finds that appointing a formal, centralized leader hurts team performance.

While these findings about formalized, planned changes are clearly important, researchers have not yet applied SAT to informal, unplanned changes that occur outside of the lab. This 
should be addressed because informal and formal networks capture fundamentally different team interaction patterns. Formal networks capture the team-level pattern on whom members are told to rely (i.e., power or authority differences) by a person external to the team. In contrast, informal networks capture with whom members choose to interact or defer (Mintzberg, 1979). Formal network changes and informal network changes are also different. Formal changes are imposed on the team, giving members little say in if and how the team changes. However, informal changes come from members implicitly or explicitly choosing to change in response to cues such as changes in mood, pressure, or the nature of their work. Consequently, informal network changes provide a more accurate window into the social psychological factors involved in network changes (Kilduff \& Lee, 2020).

Accordingly, we extend SAT to informal network changes by grounding our study in informal hierarchy strength changes in self-managed project teams. Studies about change must theorize about time (Arrow et al., 2004), and evidence shows that project teams change at predictable times (Gersick, 1988, 1989; Humphrey \& Aime, 2014). Thus, our context of selfmanaged project teams is well-suited for this initial application of SAT to unplanned, informal changes.

In particular, we extend SAT by incorporating the idea that, where formal changes are externally motivated, informal changes are usually preceded by an internalized stimulant (Argote et al., 1989). More specifically, we propose that increases or decreases in pressure impact the extent to which informal hierarchy subsequently strengthens or weakens. In project teams, the need to complete work by a deadline creates an inherent sense of pressure at the midpoint that was not present before it (Gersick, 1988, 1989; Seers \& Woodruff, 1997). This suggests that informal hierarchy should weaken as project teams approach the midpoint and strengthen after it. 
We also extend SAT's principle of asymmetric adaptability to include the rate of change as a key variable in explaining performance. Formal changes do not tend to vary much in how quickly they occur; at least on paper, formal changes are in place as soon as they are imposed on the team. In contrast, informal changes vary widely in how fast they happen because they are at members' discretion (Boumgarden et al., 2012). Therefore, we extend the asymmetric adaptability principle to also consider the rate at which changes occur. More specifically, we propose that the faster informal hierarchy strengthens diverts more attention away from task demands and harms performance.

Finally, we build upon prior examinations of SAT that show that inclusive discussion can help teams to have more productive changes (Beersma et al., 2009; Johnson et al., 2006). In particular, we propose that, because the most influential team member's personality can affect the inclusivity of discussions, the most influential team member's personality can play a role in the rate of informal hierarchy strength change. We suggest that teams with a most influential extravert will have a more dramatic strengthening of their informal hierarchy because most influential extraverts tend to dominate discussion. We further suggest that, because influential neurotics tend to be inclusive, teams with most influential neurotics have more gradual strengthening of their informal hierarchy. Our illustrative model is in Figure 2.

---- Insert Figure 2 about here ----

\section{Informal Hierarchy Strength}

While the long history of delineating between power, authority and deference (Fiske \& Berdahl, 2007; Magee \& Galinsky, 2008; Thibaut \& Kelley, 1956) is outside of the scope of this paper, highlighting the differences between those concepts can help to clearly conceptualize informal hierarchy strength. Power is having resources that allow one to have "asymmetric 
control over another's valued outcomes" (Fiske \& Berdahl, 2007, p. 679; Thibaut \& Kelley, 1956). Just about any resource can endow one with power as long as the other person values it. For example, authority or prominence granted to an individual from the organization (French $\&$ Raven, 1959) can be a source of power that person A has over person B as long as B relies on A to use A's authority to improve an outcome for B. Importantly, having power does not mean that it must be used to change another's behavior; power is simply control over a valued resource such as authority and does not involve volition.

Deference, however, involves volition in the form of one person modifying another's behaviors. Deference is defined as one person changing their actions in response to the wishes of another (Fiske \& Berdahl, 2007); when A defers to B, A does as B wishes. In short, authority and power differ from deference in that authority and power do not involve volition, but deference is about volition in the form of having one's behavior changed (Fiske \& Berdahl, 2007; Thibaut \& Kelley, 1956).

To help make this distinction clearer, consider the chair of an academic committee. The chair has authority in the form of the title "chair," which grants that person prominence in the committee. And only if that chair is able to control a member's valued outcome does the chair have power over that member. Similarly, that member is only said to defer to the chair if that member changes behaviors in accordance with the chair's wishes regardless of if the chair used authority or power to change the member's behaviors or not.

The distinction between authority and deference is central to delineating between informal and formal hierarchy. Informal hierarchy is based on dyadic differences in deference, but formal hierarchy is based on difference in authority (Magee \& Galinsky, 2008). Because informal and formal hierarchy are based on different constructs that do not perfectly align (Fiske \& Berdahl, 
2007), informal and formal hierarchy do not always have the same strength. Indeed, Oedzes and colleagues (2019) showed that teams have a stronger informal hierarchy when they do not have a formal hierarchy.

Importantly, deference is not primarily a characteristic of an individual member, but rather a property of the dyadic relationship between two members (Emerson, 1962). Consequently, informal hierarchy strength is not a linear network where all members defer to one member, nor is it a network of subgroups where some members receive deference and others do not (Krackhardt, 1994; Martin, 2009). Instead, an informal hierarchy is a network pattern of dyadic deference relations within a group (Chase, 1980) with informal hierarchy strength being the extent to which a group's dyads have asymmetric direct and indirect deference (Oedzes et al., 2019) $)^{1}$

Because deference involves a tradeoff between making an efficient decision and having autonomy (Fein, 2012; Tiedens et al., 2007) and the extent to which teams value autonomy over efficiency depends on contextual cues that change over time (Gersick, 1988, 1989; Knight, 2015), informal hierarchy strength should also change over time. However, quantitative informal hierarchy strength studies, which are summarized in the Appendix, have yet to investigate informal hierarchy strength changes. Indeed, the Appendix does not contain a single study that measures informal hierarchy strength at more than one point in time.

This needs to be addressed in order for informal hierarchy research to reflect the wellestablished reality that teams change over time (Marks et al., 2001). Moreover, SAT research indicates that changes in networks can affect performance more than the network at any given time (Hollenbeck et al., 2011; Moon et al., 2004). This suggests that informal hierarchy strength changes may impact performance more than informal hierarchy strength at a given point in time. 
Because the predominant cross-sectional approach to informal hierarchy strength has failed to find a consistent relationship between informal hierarchy strength and performance (For a metaanalysis, see Greer et al., 2018), studying changes may be more practically relevant than the current static approach. Consequently, the remainder of this paper extends SAT to develop and then test a theoretical model of informal hierarchy strength changes and their effect on performance.

\section{How Pressure Affects Informal Hierarchy Strength Changes}

SAT proposes that "formal, external interventions" disrupt the tendency of team networks to become less ordered and stimulate teams to put in the additional energy needed to become more ordered (Johnson et al., 2006, p. 106). Notably, research has shown that informal stimuli such as stress (Argote et al., 1989; Torrance, 1954) and pressure (Gardner, 2012) can also lead to informal networks implicitly becoming more ordered. Therefore, we extend SAT to propose that informal networks can also become more ordered after informal stimulants.

Consistently, we propose that informal hierarchy strengthens following an increase in pressure - feeling urgency to make progress or perform (Gardner, 2012). Pressure energizes teams to efficiently coordinate their work (Gardner, 2012). Teams feel as though they are efficiently coordinating when informal hierarchy is stronger, because some members regularly deferring to other members reduces the time spent debating how work should be done and increases the time spent doing the work (Anderson \& Kilduff, 2009; Bunderson \& Sanner, 2020; Halevy et al., 2012). For example, Fein (2012) shows that nomads' tacitly change to a stronger informal hierarchy after they feel pressure to move locations and that the stronger informal hierarchy helps the nomads efficiently coordinate their move. Also, it takes time for informal networks to change as members must adjust to new deference patterns, which suggests that 
informal hierarchy becomes stronger after pressure increases. Stated formally:

Hypothesis 1: There is a positive relationship between pressure and subsequent informal hierarchy strength.

The relationship between pressure and informal hierarchy strength has implications for the timing and direction of project teams' informal hierarchy strength changes. Project teams have project deadlines that inextricably link awareness of the limited amount of time remaining to pressure; shared awareness of the limited time remaining increases shared pressure (Gersick, 1988, 1989). More specifically, prior research shows that project teams pay little attention to time until the midpoint. At the midpoint, project teams predictably become acutely aware of their limited remaining time and feel heightened pressure (Gersick, 1988, 1989; Knight, 2015; Seers \& Woodruff, 1997). In other words, most project teams start off with low pressure then have high pressure at the midpoint.

In line with SAT's implication that informal hierarchy will weaken unless teams feel stimulated to strengthen their informal hierarchy, we propose that project teams feeling little pressure at the beginning (Gersick, 1988, 1989) is followed by their informal hierarchy weakening. The midpoint then acts as an "alarm clock, heightening team members' awareness that their time is limited, stimulating them" (Gersick, 1988, p. 34) and increasing the amount of pressure they feel from the midpoint to project completion (Gersick, 1989). Because an increase in pressure is followed by informal hierarchy strengthening, informal hierarchy should strengthen after the midpoint. Together, this suggests that informal hierarchy weakens in the beginning of the project and strengthens after the midpoint in project teams. Stated formally:

Hypothesis 2: Informal hierarchy strength follows a curvilinear pattern in project teams, weakening as project teams approach the midpoint and strengthening after the midpoint. 


\section{The Effect of the Rate of Informal Hierarchy Strength Change on Performance}

In considering asymmetric adaptability, SAT currently focuses solely on the direction of change, stating that shifts to more ordered networks harm performance (Hollenbeck et al., 2011; Moon et al., 2004). However, despite our hypothesis that most project teams shift to more ordered networks in the form of strengthening their informal hierarchy after the midpoint, project teams vary in how well they perform. That is, there is little variance in the direction of informal hierarchy strength changes to explain differences in performance.

Project teams do, instead, vary in their rate of informal hierarchy strength change because they vary in the amount of increased pressure they feel at the midpoint. Moreover, the rate of change can have important performance implications (Arrow, 1997; Arrow et al., 2004; Morgeson et al., 2015). Rapid changes to team networks disrupt the interaction patterns and routines that are foundational to feelings of control (Folkman, 1984). To regain a sense of control, teams tend to divert effort away from task completion and towards making sense of the change (Gersick \& Hackman, 1990). SAT suggests that this is particularly problematic for increasing order in team networks, because increasing order requires more effort to create more predictable deference relations. Accordingly, we extend SAT by suggesting that rapid increases in order harm performance more than gradual increases in order.

This should apply to the rate of informal hierarchy strength change- the amount that the informal hierarchy strengthens or weakens over a period of time. Indeed, abrupt changes in informal hierarchy strength "distract members from the shared goals" that facilitate coordinated progress by redirecting members' attention to figuring out their place in the informal hierarchy (Bunderson \& Sanner, 2020, p. 37). In contrast, teams that more gradually strengthen their informal hierarchy buffer against these destructive effects and may be able to benefit from 
informal hierarchy strength facilitating coordination. Indeed, Bunderson and Sanner (2020) showed that minimal informal hierarchy strengthening can substantially facilitate forward progress. Moreover, a gradual strengthening of informal hierarchy gives members more time to identify and adjust to each new deference pattern thereby making gradual informal hierarchy strengthening less disruptive (Gersick \& Hackman, 1990). In this case, teams divert less attention away from task completion, which is the primary reason SAT proposes networks becoming ordered harms performance (Hollenbeck et al., 2011; Moon et al., 2004). In sum, because more gradual strengthening of informal hierarchy may minimally distract from task completion and substantially improve forward progress, we propose that the rate of informal hierarchy strengthening is negatively related to performance. Stated formally:

Hypothesis 3: There is a negative relationship between performance and the rate that informal hierarchy strengthens after the midpoint.

\section{Effect of the Most Influential Person on Informal Hierarchy Strengthening}

Prior tests of SAT show that it is difficult for teams to have productive network changes. Network changes usually stem from an implicit, shared understanding of how processes should change, and it can be difficult for teams to develop that shared understanding (Johnson et al., 2013). One way that SAT studies have shown that teams can have more productive changes is to have inclusive discussions that help members develop a shared understanding of how they should change. These inclusive discussions can also help members shed previously held expectations that can get in the way of developing an accurate understanding of the extent that the team should change (e.g., Beersma et al., 2009). Indeed, Johnson et al. (2013) show that even teams whose networks are deliberately misaligned must have inclusive discussions to properly change their network. In short, extensions of SAT suggest that inclusive discussions help 
members develop a shared understanding of how they should change, and consequently, help them change their network in a more productive way. Because more gradual strengthening of informal hierarchy after the midpoint is more productive, SAT would then suggest that inclusive discussion will help teams more gradually strengthen their informal hierarchy.

Notably, these prior examinations of SAT have been tested by having an experimenter direct teams to have inclusive discussions in certain experimental conditions. Because we examine the informal dynamics of self-managed project teams, there is no experimenter who urges the team to have inclusive discussions. Instead, self-managed project teams are guided by their most influential member - the member whom teammates defer to the most on average (Bunderson \& Reagans, 2011). Members inherently look to the most influential member for direction as a response to an increase in pressure (Demange, 2004), such as the increase in pressure selfmanaged project teams experience at the midpoint (Gersick, 1988, 1989). The direction the team gets from its most influential member then impacts how members interact with each other, including how inclusive their discussions are (Bunderson \& Reagans, 2011; Keltner et al., 2008). Therefore, similar to experimenter-directed input, the most influential member can foster inclusive discussions that affect whether the team gradually strengthens their informal hierarchy.

Moreover, because most influential members do not need to defer to anyone, they generally feel free to act in accordance with their personality (Chen et al., 2001). This suggests that the most influential member's personality fosters or limits inclusive discussions thereby affecting how gradually teams strengthen their informal hierarchy. Notably, prior research suggests that two personality characteristics, extraversion and neuroticism, are particularly predictive of how the most influential person will affect inclusive discussion (Bendersky \& Shah, 2013). Bendersky and Shah (2013, p. 388) posit that extraversion and neuroticism are the two 
characteristics that are most related to whether leaders dominate discussions instead of showing "concern about how others" think the team should proceed. Most influential extraverts tend to be domineering, which suppresses inclusive discussions (Bendersky \& Shah, 2013; Grant et al., 2011). In contrast, most influential neurotics tend to ask for input from all members thereby encouraging inclusive discussions (Bendersky \& Shah, 2013; Elliot \& Thrash, 2002).

When the most influential member is extraverted - "assertive, talkative, and active" (Barrick \& Mount, 1991, p. 3) — that individual is likely to direct tasks and activities. When highly extraverted people have influence, they tend to dominate and control the team (Grant et al., 2011). Extraverts are often poor listeners and are unreceptive to others' input (Grant et al., 2011) as they attempt to direct others' behaviors (Fragale, 2006). This suggests that most influential extraverts may be more inclined to direct work and reduce inclusive discussion (Grant et al., 2011). Because SAT posits that inclusive discussion is needed for productive network changes (Beersma et al., 2009; Johnson et al., 2013), such as informal hierarchy gradually strengthening after the midpoint, we propose that teams with more extraverted most influential members will strengthen their informal hierarchy more rapidly after the midpoint. Stated formally:

Hypothesis 4a: The extraversion of the most influential member amplifies informal hierarchy strengthening after the midpoint.

In contrast, when the most influential member is highly neurotic_- "worried and insecure" (Barrick \& Mount, 1991, p. 4) — that person will feel a need for input and approval before making recommendations (Elliot \& Thrash, 2002). By showing that all members' support is needed, a most influential neurotic promotes the inclusive discussion that SAT suggests will dampen informal hierarchy strengthening. Neuroticism is strongly associated with a desire to avoid social disapproval or being perceived as incompetent (Elliot \& Thrash, 2002). Influential 
neurotics minimize the risk of being socially sanctioned by actively encouraging participation and ideas from others before making recommendations (Elliot \& Thrash, 2002). That is, influential neurotics promote inclusive discussions. Consistent with SAT's idea that inclusive discussion facilitates productive network changes (Beersma et al., 2009; Johnson et al., 2013), such as informal hierarchy strengthening gradually, we propose that teams whose most influential member is more neurotic should have a more gradual strengthening of their informal hierarchy after the midpoint. Stated formally:

Hypothesis 4b: The neuroticism of the most influential member attenuates informal hierarchy strengthening after the midpoint.

\section{Methods}

Subjects were students from an upper-level undergraduate management course at a private American university. They were assigned to teams formed by the professor to maximize functional diversity across concentrations and majors in an attempt to mirror the realism of work contexts. The teams were then assigned to semester-long consulting projects in which each team worked with a local organization to complete a project that had the potential to meaningfully impact the organization. For example, teams created strategic plans, developed and implemented marketing strategies, and redesigned organizational programs.

While there were some differences in task content, there were notable similarities between the teams. First, all teams were self-managed, with guidance coming primarily from the external clients. Second, all projects were similarly knowledge intensive, with all teams being required to collect data, solve complex problems, and manage interdependencies. Third, all teams had strict project deadlines. Fourth, grading was consistently weighted, with the consulting project counting for about half of the students' final grade - a meaningful incentive to perform well. 
Although student teams, the fact that they worked on a real project that their clients intended to implement increases the generalizability of our findings to the prevalent use of project teams in organizations. Indeed, the clients themselves proposed the projects with the goal of creating an impactful outcome, rather than designing the projects primarily to serve student learning. Moreover, the professor interacted minimally with the clients; the teams were expected to work directly for their client as they would if they were a paid consulting project team.

The sample consisted of 234 members on 55 teams. Teams consisted of four or five members $(M=4.38, S D=.59)$. The sample was predominantly male $(65.3 \%)$ and white $(72.8 \%)$, with an average age of 21.17 years $(S D=1.62)$. The project ran for the duration of the semester, roughly 15 weeks. Before the projects started (T0), the students took a survey on their personality (95\% response rate). Next, the participants completed three surveys for the informal hierarchy strength measure that were timed to coincide with meaningful periods of the project lifecycle. The first survey (T1) occurred early in team life (94\% response rate). A second survey was administered at the temporal midpoint (T2) (96\% response rate). A final survey was administered near the end of the project (T3) (97\% response rate). The clients rated the teams' performance following project completion (T4) (100\% response rate).

It is worth noting that the surveys were designed to be part of students' learning, rather than implemented solely as part of this study. Specifically, students used the aggregated results of the surveys to complete a reflection paper linking their team responses to course concepts. Students were asked to allow their responses to be used for research in accordance with protocol that followed established ethical guidelines and the school's institutional review board (IRB832014: Influence structure changes over time). Consistent with IRB requirements, students were allowed to opt out of the research study and still complete the surveys for their required course activities. 


\section{Measures}

\section{Informal Hierarchy Strength}

Similar to previous research, informal hierarchy strength is maximized when every dyadic pairing has asymmetric deference (Bunderson et al., 2016; Oedzes et al., 2019). Accordingly, we adopted a dyadic approach to measure deference asymmetries that was then aggregated into a network measure of informal hierarchy strength. More specifically, we calculated Krackhardt's (1994) informal hierarchy strength index in three steps. First, we asked members to rate how much they deferred to each other member. Second, we organized members' responses into a sociomatrix to classify each dyad as having symmetric or asymmetric deference. Third, we calculated the informal hierarchy strength index, which captured the proportion of dyads with asymmetric direct and indirect deference.

Participants rated the extent to which they deferred to each team member using three items that included rating how much each member "influenced you or your project work," "influence your mood in the project team," and the extent to which "you deferred to this person on project-related matters" during each period. Each teammate was rated on a scale from 1 (not at all) to 7 (a lot). We calculated the deference relations that underlie informal hierarchy strength based on one member's acceptance of another member's influence, not the extent to which individuals felt others deferred to them. This approach is consistent with research showing that the deference "relations that underlie hierarchy are based on the acceptance by one member of another member's influence over her or him" (Bunderson et al., 2016, p. 1268). The three items were averaged to obtain one dyadic rating for each team member's deference to each other member of the team at T1 $(\alpha=.87)$, T2 $(\alpha=.87)$, and T3 $(\alpha=.85)$.

Second, we organized these responses in a sociomatrix where each rating $\mathrm{x}_{\mathrm{ij}}$ represented 
member $\mathrm{j}$ deferring to member $\mathrm{i}$, as judged by member $\mathrm{j}$. Because dichotomous measures were required to calculate informal hierarchy strength, we collapsed responses into two categories. $31 \%$ of responses indicated deference ratings greater than moderate ( 5 or above), so we collapsed the three highest response categories in the sociomatrix to create a dichotomous deference variable in which $0=$ "not at all" to "slightly" and $1=$ "moderate" to "a lot." A similar categorization was used by Bunderson et al. (2016).

Third, we computed informal hierarchy strength using Krackhardt's (1994) network hierarchy measure: $1-[\mathrm{V} / \max (\mathrm{V})]$, where $\mathrm{V}$ is the number of dyads in the network that have symmetric deference (A defers to $\mathrm{B}$, and $\mathrm{B}$ defers to $\mathrm{A}$, directly or indirectly) and $\max (\mathrm{V})$ is the total number of dyads. Consistent with informal hierarchy strength being maximized when all dyads have asymmetric deference, informal hierarchy strength values represent the proportion of dyads with asymmetric deference, ranging from 0 (all connected pairs have symmetric deference) to 1 (all connected pairs have asymmetric deference).

\section{Pressure}

Pressure was measured at T1 and T2 using a three-item scale adapted from Durham and colleagues (2000) (T1: $\alpha=.78 ; \mathrm{T} 2: \alpha=.76)$ to be about pressure in general and to specify the time frame in question. All responses were rated on a 7-point scale from 1 (strongly disagree) to 7 (strongly agree). The items were "I felt pressure to complete our work this week," "The amount of work I have to do interferes with the quality I want to maintain," and "This week we had too much to do in too little time." Because members' interrater agreements (T1: ICC1 $=.43$, $\mathrm{ICC} 2=.75 ; \mathrm{T} 2$ : ICC $1=.54, \mathrm{ICC} 2=.83$ ) were above the recommended thresholds (Burke et al., 1999), individual pressure scores were then averaged to compute one pressure rating for each team at each point in time. 


\section{Extraversion and Neuroticism of the Most Influential Member}

Subjects were surveyed about their personality characteristics before beginning the project. We measured personality variables using the NEO Five Factor Inventory (Costa \& McCrae, 1992). All responses are on a 7-point scale from 1 (strongly disagree) to 7 (strongly agree). Neuroticism $(\alpha=.83)$ and extraversion $(\alpha=.91)$ were each measured using 10 items. A sample extraversion item is "I know how to captivate people." A sample neuroticism item is "I am not easily bothered by things" (reverse-coded). Consistent with the most influential person at the midpoint being defined as the person who teammates deferred to the most on average, we identified the most influential member by averaging the dyadic deference ratings for each team member at the midpoint (T2) and then selected the member who was deferred to the most on average in the team.

Two teams had two people who tied for having been deferred to the most at T2. In those teams, we averaged the tied members' extraversion and neuroticism. Excluding those teams from the analysis did not change any estimate's direction or significance. We excluded three teams from the analysis because their most influential member at T2 did not complete an initial personality survey, so their extraversion and neuroticism scores were unavailable.

\section{Team Performance}

Because our sample included various projects that were designed to meet clients' needs, the professor asked the client supervisors to recommend a grade for each team's performance. Primarily to minimize the effect of client differences in expectations on students' grades, all of the clients were trained by the same professor on the grading criteria before they submitted their project proposal. They were again reminded of class expectations when they were sent the evaluation. As part of the client's training, they were instructed that students' grades were out of 
100 possible points with letter grades corresponding to 10-point ranges. They were reminded of that in the prompt before starting the evaluation. ${ }^{2}$

Clients then submitted the evaluation in two parts. First, they completed Van der Vegt and Bunderson's (2005) five-item scale for project team performance $(\alpha=.94)$. This scale asked client supervisors to consider the team's performance along five criteria: efficiency, quality, overall achievement, productivity, and mission fulfillment. Second, clients wrote at least a paragraph on each of the following topics: team activities, project outcomes, and reasons for the recommended grade. Because fair grading is the professor's responsibility, the professor reviewed all the recommended grades along with the clients' explanations. In a few cases where the grade recommended did not seem consistent with explanation of the grade, the professor worked with the client to better understand the recommended grade and, if needed, worked with the client to change it. This should minimize the extent to which having multiple raters influences our results.

It also worth noting that team members graded each other's performance after the project was completed, and this evaluation counted for $10 \%$ of their final grade. These data are not included in the team-performance measure.

\section{Controls}

Given that size varied across teams and can affect informal hierarchy strength, we included team size as a control variable in all analyses. We also ran our models with the demographic control variables of average age, as well as gender and race diversity, as they are linked with perceptions of deference (Berger et al., 1986). Because these controls were correlated with informal hierarchy strength and performance, we included them in the reported models. We also included the average ratings of deference within the team to account for the possibility that 
average deference ratings may have affected informal hierarchy strength. Average deference was calculated as the mean rating of deference across all team members within each group. For the hypotheses involving the most influential member's personality, we also controlled for the other three personality measures of the most influential member: agreeableness $(\alpha=.78)$, openness to experience $(\alpha=.81)$ and conscientiousness $(\alpha=.89)$, which were also measured using the NEO Five Factor Inventory (Costa \& McCrae, 1992).

\section{Results}

Table 1 presents the correlations among study variables. In general, the pattern and direction of the means and correlations were in line with expectations. Consistent with previous research (Gersick, 1988, 1989), a paired sample $t$-test comparing pressure between the early phase and midpoint showed a significant increase in pressure $(t(55)=5.30, p<.001)$ from the early phase $(M=2.67, S D=.64)$ to the midpoint $(M=3.39, S D=.67)$. Moreover, 48 of 55 teams $(87 \%)$ in our sample experienced higher pressure at the midpoint than at the beginning.

In line with our expectations, teams started with moderate informal hierarchy strength $\left(M_{\mathrm{T} 1}=\right.$ $.38, S D=.23)$ that weakened at the midpoint $\left(M_{\mathrm{T} 2}=.19, S D=.13\right)$ and then strengthened $\left(M_{\mathrm{T} 3}=\right.$ $.51, S D=.24)$. Further underscoring that the vast majority of teams have a stronger informal hierarchy after the midpoint, only four of 55 teams (7\%) weakened informal hierarchy after the midpoint.

\section{---- Insert Table 1 about here ----}

It is also worth noting that the absolute amount of informal hierarchy strength was not statistically significantly related to performance at any of the three points in time (T1: $r=.08, p$ $=.554 ; \mathrm{T} 2: r=-.10, p=.488 ; \mathrm{T} 3: r=-.14, p=.317)$. This is consistent with SAT's proposition that the amount of a team network is not as important for performance as changes in it. 
The descriptive statistics also highlight the similarity between our student teams and nonstudent teams. Bunderson and colleagues (2016) measured the informal hierarchy strength of 75 non-student teams in 56 organizations and found similar levels of informal hierarchy strength (Bunderson et al. (2016): $M=.41, S D=.36$; current study: $M=.36, S D=.24$ ).

\section{Effect of Pressure on Informal Hierarchy Strength}

Hypothesis 1 proposed that pressure would be positively related to subsequent informal hierarchy strength. Because we hypothesized about how teams respond after feeling pressure, we ran regressions to predict informal hierarchy strength using the pressure the team felt in the prior period (i.e., pressure at $\mathrm{T} 1$ as the predictor of informal hierarchy strength at $\mathrm{T} 2$; pressure at $\mathrm{T} 2$ as the predictor of informal hierarchy strength at T3). We used hierarchical linear modeling (HLM; Raudenbush \& Bryk, 2002) to account for teams providing multiple ratings of pressure over time, creating a dependency in observations that may bias OLS estimates. Table 2 presents the results of the HLM analysis. Model 1 adds the controls, and Model 2 tests Hypothesis 1 by adding the effect of pressure in the preceding project phase. Models 3 and 4 test the robustness of Model 2's findings by adding prior period informal hierarchy strength and the current pressure as controls. Models 2-4 support Hypothesis 1 by showing that previous pressure significantly increases subsequent informal hierarchy strength (Model 2: $\beta=.13, p<.001$; Model 3: $\beta=.12, p$ $<.001$; Model 4: $\beta=.11, p<.001)$.

---- Insert Table 2 about here ----

\section{Growth Modeling}

In order to test our Hypotheses 2 and 4, which are about changes in informal hierarchy strength over time, we used growth modeling to analyze the patterns of change. Growth modeling is a technique used to describe and predict differences in change (Hoffman, 2015). In 
contrast to repeated measures analysis of variance, which is most useful for partitioning withinand between-group differences in a construct over multiple observations, growth modeling is a technique specifically designed to estimate "(a) the average pattern of change in a construct over time, (b) the extent to which observations vary in their patterns of change in that construct, and (c) the significance of drivers of different patterns of change" (Hoffman, 2015; Knight, 2015, p. 108; Singer \& Willett, 2003). Because Hypotheses 2, 4a, and 4b are about average patterns of change and drivers of it, growth modeling is more appropriate for our purposes.

In growth modeling, change over time is represented by the change intercept (the average level of the focal construct at a specific point in time) and the change slope (how much the construct changes over time) (Hoffman, 2015). In our tests, the intercepts represent the informal hierarchy strength at a point in time, while the slope represents the rate of change of informal hierarchy strength over a unit of time (in this case, each stage of project life). In all the growth model analyses, we used bootstrapping to calculate standard errors, as recommended for small sample sizes (Chernick, 2011). We examined the $95 \%$ confidence interval (CI) of the 10,000 bootstrap estimates, and we would have rejected a hypothesis if the interval had included zero.

Because Hypotheses 2 and 4 refer to different focal times, we changed the reference points to examine those specific points in time. By centering time, we can focus parameter estimates on specific points in the change trajectory (Biesanz et al., 2004). To test Hypothesis 2 regarding the shape of the trajectory for early and late times, we coded time so that the change intercept represents informal hierarchy strength early in the team's life, and growth aligns with the usual progression of the project life (i.e., $\mathrm{T} 1=0, \mathrm{~T} 2=1, \mathrm{~T} 3=2$ ). To test Hypothesis 4 regarding the effect of the most influential member's extraversion and neuroticism on the growth of informal hierarchy strength from the midpoint through late team life, we coded time such that the change 
intercept represents informal hierarchy strength late in team life (i.e., T1 = -2, T2 = -1, T3= 0). Coding for late time means that the linear slope represents the growth of informal hierarchy strength late in team life (near the end of the project). In all analyses, we grand mean-centered predictor variables, unless otherwise specified.

For Hypotheses 2 and 4 in which time is the independent variable, we summarized the growth models in Table 3 and 4. In Table 3, we use the early time coding appropriate for Hypothesis 2, and in Table 4 we use the late time coding appropriate for Hypothesis 4.

\section{Informal Hierarchy Strength Change over Time}

Hypothesis 2 proposed that teams change their informal hierarchy strength over the course of project life such that informal hierarchy weakens early in the project and then strengthens after the midpoint. Because we are interested in curvilinear changes over time, we used a quadratic model to test informal hierarchy strength changes. In particular, we used Bliese and Ployhart's (2002) model-building approach to determine the base growth curve that best fit the data. With this approach, we started by graphing the data, then increased the complexity of models to identify whether the basic pattern of change over time was consistent with our expectations and whether teams varied in their slope of change in informal hierarchy strength over time. To ensure that our predictors were meaningful, we also compared log likelihood ratios (deviances) between models through ANOVA tests (Bliese \& Ployhart, 2002).

We used a baseline model that includes the fixed effects of time and a random intercept for the team groupings. Although teams varied in their informal hierarchy strength early in team life, between-team grouping accounted for only $3.2 \%$ of the variance in informal hierarchy strength, which suggests that most of the variability in informal hierarchy strength is accounted for by within-group changes. We then included the random effect of time so that the slope associated 
with time can randomly vary among teams. Comparing this model with the previous model returned a significant likelihood ratio $\left(\chi^{2}(2)=54.70, p<.001\right)$, indicating that the model with the random slope fits the data significantly better than does the model without the random slope.

In Table 3, Model 1 reports time and time-squared as predictors. Model 2 then more robustly tests the first hypothesis by adding controls. We found that a model (shown in Model 1 of Table 3) containing a linear effect of time $(B=-.45 ; 95 \% \mathrm{CI}=-.59,-.33)$, a quadratic effect of time (B $=.26 ; 95 \% \mathrm{CI}=.18, .32$ ), a random intercept term, a random linear slope term, and a covariance term for the relationship between the random intercept and random slope best fit the data. We include a fixed quadratic effect of time, which means that only the linear effects of time are conditional; there is no variation between teams in the quadratic shape of their informal hierarchy strength trajectories. Instead, only their linear rates of changes vary between teams, and the linear random effect denotes the instantaneous rate of change specifically at the time coded as 0 . The correlation between the intercept and slope $(r=-.53)$ indicates that teams started out with high informal hierarchy strength early in life and tended to weaken their informal hierarchy over time. The linear component of time explained $5.1 \%$ of variance in informal hierarchy strength beyond differences between the groups. Notably, the quadratic effect of time explained far more variance in informal hierarchy strength, $42 \%$, which makes the quadratic model a better fit.

\section{---- Insert Table 3 about here ----}

Figure 3 shows the predicted curvilinear change in informal hierarchy strength over time. Teams start with moderate informal hierarchy strength that weakens as the team approaches the midpoint. After the midpoint, informal hierarchy strengthens until the project deadline. Thus, Hypothesis 2 was supported 
---- Insert Figure 3 about here ----

\section{Most Influential Member's Effect on Informal Hierarchy Strength Changes}

In Hypotheses $4 \mathrm{a}$ and $4 \mathrm{~b}$, we proposed that the extraversion and neuroticism of the teams' most influential member at the midpoint would moderate the late strengthening of informal hierarchy. Specifically, we expected that the most influential person's extraversion would enhance the strengthening of informal hierarchy after the midpoint, while the most influential person's neuroticism would attenuate the strengthening of informal hierarchy after the midpoint.

In Table 4, Model 1 starts the analysis with the time coding appropriate for Hypothesis 4 by adding time and time-squared as predictors. Model 2 adds controls. Model 3 adds the most influential person's personality variables, and Model 4 tests Hypothesis 4a by adding the interaction term between time and the most influential person's extraversion. Models 5 tests Hypothesis $4 \mathrm{~b}$ by adding the interaction between time and the most influential person's neuroticism.

\section{---- Insert Table 4 about here ----}

As seen in Model 4 of Table 4, the interaction of the most influential member's extraversion and time was, consistent with Hypothesis $4 \mathrm{a}$, positive $(\mathrm{B}=.03,95 \% \mathrm{CI}=.01, .07)$, and over $95 \%$ of the bootstrap estimates were positive. In Figure 4, we graphed the predicted trajectories after the midpoint for teams whose most influential person was relatively low $(-1 S D)$ and relatively high $(+1 S D)$ in extraversion and used simple slope analysis to examine the pattern of results (Hoffman, 2015). Supporting Hypothesis 4a, teams whose most influential person was more extraverted experienced a more dramatic strengthening of their informal hierarchy than did those whose most influential member was less extraverted (High extraversion: $\mathrm{B}=.68, p<.001$; Low extraversion: $\mathrm{B}=.57, p<.001$ ). 
---- Insert Figure 4 about here ----

Model 5 of Table 4 shows that the interaction between the most influential members' neuroticism and time was, consistent with Hypothesis $4 \mathrm{~b}$, negative $(\mathrm{B}=-.06,95 \% \mathrm{CI}=-.10$, .01 ), and over $95 \%$ of the bootstrap estimates were negative. In Figure 5, we graphed the predicted trajectories after the midpoint for teams whose most influential person was relatively low $(-1 S D)$ and relatively high $(+1 S D)$ in neuroticism and used simple slope analysis to examine the pattern of results (Hoffman, 2015). Teams whose most influential person was high in neuroticism experienced a less dramatic strengthening of informal hierarchy than did those whose most influential person was low in neuroticism (High neuroticism: $\mathrm{B}=.57, p<.001$; Low neuroticism: $\mathrm{B}=.69, p<.001)$. Together, these findings indicate that the most influential member's neuroticism keeps informal hierarchy from strengthening as dramatically after the midpoint. Thus, Hypothesis 4b was supported.

---- Insert Figure 5 about here ----

\section{Informal Hierarchy Strength Change and Team Performance}

In Hypothesis 3, we predicted that rapid strengthening of informal hierarchy over the second half of the team's life would negatively impact team performance. We calculated each team's rate of informal hierarchy strength change using growth modeling. Allowing the relationship between time and performance to vary across teams provides a measure - the Bayes estimatorof each team's rate of informal hierarchy strength change (see Knight, 2015). As suggested by Knight (2015), we extracted the Bayes estimators from an unconditional growth model of informal hierarchy strength with time coded such that the intercept represented informal hierarchy strength late in a team's life. The estimators provided a measure of each team's rate of informal hierarchy strength change after the midpoint, such that a higher estimator indicates a 
more dramatic strengthening of informal hierarchy after the midpoint.

We used OLS regression models to predict team performance and test Hypothesis 3. Table 5 presents the results of the OLS analysis of performance. In it, Model 1 adds the controls and Model 2 tests Hypothesis 3 by adding the Bayes estimator for the rate of informal hierarchy strength change. As Model 2 in Table 5 shows, the rate of informal hierarchy strength change after the midpoint was negatively related to team performance $(\mathrm{B}=-162.71, p=.021)$, explaining $9 \%$ of the variance in team performance beyond the controls. Thus, Hypothesis 3 was supported.

---- Insert Table 5 about here ----

\section{Discussion}

Our results highlight the importance of using SAT to move informal hierarchy strength research away from the current static theoretical models and toward a more dynamic approach. Consistent with SAT's idea that networks become more/less ordered after high/low stimulation, we find that high pressure is followed by informal hierarchy strengthening. In project teams that start off with low pressure and have higher pressure at the midpoint, we show that informal hierarchy weakens as teams approach the midpoint and strengthens after it without any formal intervention. We also find that time explains $42 \%$ of the variance in informal hierarchy strength in our teams. Therefore, our results demonstrate that the implications of SAT are correct: a dynamic approach is necessary to accurately conceptualize and test models of informal hierarchy strength.

Our findings also emphasize the importance of SAT's principle that changes in networks affect performance more than the network at any point in time. Consistent with a recent metaanalysis (Greer et al., 2018), we find that informal hierarchy strength does not meaningfully 
predict performance at any of the three points in time at which we measured it. In contrast, we find that the rate of informal hierarchy strength changes explained $9 \%$ of the variance in teams' performance. This stark contrast suggests that dynamic theoretical models may more meaningfully capture informal hierarchy strength's effect on performance than the more pervasive static models.

Lastly, our results are consistent with SAT's idea that inclusive discussion helps teams change their network in a more beneficial way and underscore the importance of the most influential member's personality in making a productive change. In particular, our results show that, likely because a most influential neurotic usually encourages inclusive discussion, a most influential member's neuroticism attenuates the rate of informal hierarchy strengthening. And likely because a most influential extravert tends to discourage inclusive discussion, we find that a most influential member's extraversion exacerbates the rate of informal hierarchy strengthening. Together, these findings point to the importance of applying SAT to study informal hierarchy strength changes' antecedents and consequences.

\section{Theoretical Contributions}

Not only do our findings suggest that informal hierarchy strength research should take a more dynamic approach, but they also suggest that SAT should be applied to develop these dynamic theoretical models. Recent reviews (Bendersky \& Pai, 2018; Bunderson \& Van der Vegt, 2018) lament that informal hierarchy strength research is hampered by a lack of theoretical coherence that makes it difficult to interpret informal hierarchy strength research holistically. Our results suggest that SAT provides a useful starting point for developing holistic theoretical models of informal hierarchy strength; we find that SAT was predictive of informal hierarchy strength changes and their consequences, even though SAT has not been applied in previous informal 
hierarchy strength research. Therefore, we advance informal hierarchy strength research by highlighting that SAT should be more central to future informal hierarchy strength research.

Relatedly, we also make two contributions to SAT. First, we extend the explanatory power of SAT to include unplanned, informal changes. Previous SAT examinations have almost exclusively focused on formal interventions such as changing task allocations (Moon et al., 2004) or rewards (Baer et al., 2010; Beersma et al., 2009) and deliberate network changes such as appointing a centralized leader (Hollenbeck et al., 2011) or changing how tasks are distributed (Moon et al., 2004). However, we show that the principles of SAT apply to an informal network - informal hierarchy strength — and that it can change without a formal intervention. This suggests that SAT should include informal as well as formal changes.

In addition, we provide key insight into one of SAT's core propositions by showing that its asymmetric adaptability principle should not simply consider the direction of change; it should also include the rate of change. SAT has been studied primarily in laboratories where change happens quickly, and such studies have found only negative consequences of shifts to more ordered networks (Hollenbeck et al., 2011; Johnson et al., 2013). In contrast, we find that gradual shifts to more ordered networks can help teams take advantage of the efficiency gains of more ordered networks. By showing that moves to ordered networks can be beneficial if done gradually, we help to sharpen SAT's asymmetric adaptability principle by showing that the rate of change is also important.

We also extend prior SAT research that demonstrates that inclusive discussions are integral to effective network changes (Beersma et al., 2009; Johnson et al., 2013) by suggesting that the most influential member's personality is a critical determinant of the team having inclusive discussions. We find that the personality of the most influential person during these shifts plays a 
role in how dramatically informal hierarchy strength changes. This not only implies that the most influential members' personality affects team discussion but also contributes an additional factor to SAT that may influence whether teams can change appropriately.

The finding that pressure strengthens informal hierarchy is also notable as it advances a fuller understanding of informal hierarchy strength beyond its consequences. The only empirical paper we were able to find that looked into antecedents of informal hierarchy strength (Oedzes et al., 2019) focused on a fixed feature of most teams, the existence of a formal leader. Pressure, on the other hand, can be influenced by tactics such as framing (Sanner \& Evans, 2019) and keeping members informed (Amiot et al., 2006). Therefore, we contribute to informal hierarchy strength research by identifying an antecedent that can be adjusted along with situational demands.

\section{Implications for Practice}

The sheer volume of practitioner-facing articles on the impact of informal hierarchy strength in teams (e.g., Sanner \& Bunderson, 2018) demonstrates managerial interest in the topic. Our findings help practitioners by providing actionable mechanisms that help teams manage informal hierarchy strength. In particular, our study suggests that teams can benefit from informal hierarchy strengthening gradually and that there are multiple ways to accomplish this. First, our finding that higher pressure leads to more dramatic strengthening of informal hierarchy implies that teams should avoid spikes in pressure. One way to accomplish this is for teams to meet regularly to discuss progress to minimize sudden increases in time awareness and pressure. Moreover, meetings usually involve progress updates and coordinating activities, which reduces the team's reliance on hierarchy to facilitate forward progress (Eisenhardt, 1989; Gersick, 1994). Therefore, frequent meetings can minimize the rate of informal hierarchy strengthening by reducing spikes in pressure and attenuating pressure's effect on informal hierarchy strengthening. 
In addition, our results show that influential members, who may or may not be formally appointed leaders, can play a large role in the effectiveness of informal hierarchy strength changes. Because the damaging strengthening of informal hierarchy is reduced by having a more neurotic or less extraverted most influential member, our findings suggest that the most influential member should be inclusive and encourage all members to participate in discussions.

\section{Limitations and Directions for Future Research}

Our research has limitations that suggest promising directions for future research. First, we look at only one type of team, self-managed project teams, because these teams have clearly specified temporal milestones that lend themselves to theorizing about the timing of informal hierarchy strength changes. While deadlines and pressure are necessary for many teams, pressure increases may be more ambiguous for teams that do not have concrete end points. Thus, future researchers should examine the effect of varying team types on the timing of informal hierarchy strength changes.

These future studies should also involve non-student teams. Though we found that the amount and distribution of informal hierarchy strength in our student teams to be similar to those in non-student teams, contextual factors that are more prevalent in non-student teams may impact informal hierarchy strength changes. For example, the student sample minimized confounds that may impact informal hierarchy strength such as the presence of a formal team leader (Oedzes et al., 2019) or fluid membership (Bunderson et al., 2014; Min et al., 2020). Examining such contextual factors may provide additional insights into informal hierarchy strength changes. Therefore, future research should develop and test theory that integrates these contingencies into our dynamic model.

One particularly important contingency to investigate is other network patterns. In Kilduff 
and Lee's (2020) recent review, they noted that "despite numerous calls to investigate network dynamics, social network research tends to rely on and emphasize stable social networks." In other words, research on change is missing for most network patterns. Moreover, network patterns can affect each other (Bunderson \& Van der Vegt, 2018). For example, changes in subgroups could affect changes in informal hierarchy strength. Therefore, future research that looks at informal hierarchy strength changes in conjunction with other network changes has the potential to both advance our understanding of informal hierarchy strength changes but also further our understanding of network changes in general.

Another limitation of our study involves the impact of informal hierarchy strength changes on external relationships. Like other researchers who relied on multiple supervisors to rate teams' performance (Bunderson et al., 2016; Qu \& Liu, 2017), we also used multiple supervisors to rate our teams' performance. However, the use of different raters may introduce unexplained variance into our results. For example, it could be that supervisors who support shared leadership view teams with more dramatic strengthening of informal hierarchy as being less effective, whereas those who support hierarchical leadership could view dramatic informal hierarchy strengthening as an indicator that the team is more effective (Evans et al., 2021). Thus, future research should systematically consider how changes in informal hierarchy strength may affect how teams are perceived by those outside of the team.

Finally, future research should measure informal hierarchy strength at additional points in time. While we attempted to collect data at times that were guided by prior theory and research (Gersick, 1989), it is possible that our conclusions would differ if we had gathered data at more frequent intervals (Mitchell \& James, 2001). More continuous measurements could uncover important micro-dynamics (Sanner \& Evans, 2019) and changes that we could not detect 
(McGrath, 1997). Thus, our study highlights the importance of studying informal hierarchy strength changes and encourages the use of dynamic models in future informal hierarchy strength research. 


\section{Notes}

${ }^{1}$ A dyad with direct asymmetric deference consists of one member who regularly defers to the recommendations of the other member of the dyad (e.g., A defers to B). A dyad with asymmetric indirect deference consists of one member (A) in the dyad who usually defers to a member outside of the dyad (C) who, in turn, defers to the other member of the dyad (B). In other words, A defers to $\mathrm{C}$ who defers to $\mathrm{B}$. Teams with a strong informal hierarchy consists of dyads where one member regularly defers to the other member directly or indirectly. In contrast, teams low on informal hierarchy strength consist of dyads whose members have similar direct or indirect deference.

${ }^{2}$ The exact wording was as follows: "This survey consists of a few questions. The average of your responses to the first set of questions where you score the students from 0 to 100 will be the students' project grade. [The University] uses a 10-point scale (A: 90-100, B: 80-89; C: 70-79; D: 60 - 69; F <60).” 


\section{References}

Amiot, C. E., Terry, D. J., Jimmieson, N. L., \& Callan, V. J. (2006). A Longitudinal investigation of coping processes during a merger: Implications for job satisfaction and organizational identification. Journal of Management, 32(4), 552-574. https://doi.org/10.1177/0149206306287542

Anderson, C., \& Kilduff, G. J. (2009). The pursuit of status in social groups. Current Directions in Psychological Science, 18(5), 295-298. https://doi.org/10.1111/j.14678721.2009.01655.x

Anderson, C., Willer, R., Kilduff, G. J., \& Brown, C. E. (2012). The origins of deference: When do people prefer lower status? Journal of Personality and Social Psychology, 102(5), 10771088. https://doi.org/10.1037/a0027409

Argote, L., Turner, M. E., \& Fichman, M. (1989). To centralize or not to centralize: The effects of uncertainty and threat on group structure and performance. Organizational Behavior and Human Decision Processes, 43(1), 58-74. https://doi.org/10.1016/0749-5978(89)90058-7

Arrow, H. (1997). Stability, bistability, and instability in small group influence patterns. Key Readings in Social Psychology, 72(1), 75-85. https://doi.org/10.1037/0022-3514.72.1.75

Arrow, H., Poole, M. S., Henry, K. B., Wheelan, S., \& Moreland, R. (2004). Time, change, and development. Small Group Research, 35(1), 73-105. https://doi.org/10.1177/1046496403259757

Baer, M., Leenders, R. T. A. J., Oldham, G. R., \& Vadera, A. K. (2010). Win or lose the battle for creativity: The power and perils of intergroup competition. Academy of Management Journal, 53(4), 827-845. https://doi.org/10.5465/amj.2010.52814611

Barrick, M. R., \& Mount, M. K. (1991). The big five personality dimensions and job 
performance: A meta-analysis. Personnel Psychology, 44(1), 1-26. https://doi.org/10.1111/j.1744-6570.1991.tb00688

Beersma, B., Hollenbeck, J. R., Conlon, D. E., Humphrey, S. E., Moon, H., \& Ilgen, D. R. (2009). Cutthroat cooperation: The effects of team role decisions on adaptation to alternative reward structures. Organizational Behavior and Human Decision Processes, 108(1), 131-142. https://doi.org/10.1016/j.obhdp.2008.07.002

Bendersky, C., \& Pai, J. (2018). Status dynamics. Annual Review of Organizational Psychology and Organizational Behavior, 5(1), 183-199. https://doi.org/10.1146/annurev-orgpsych032117-104602

Bendersky, C., \& Shah, N. P. (2012). The cost of status enhancement: Performance effects of individuals' status mobility in task groups. Organization Science, 23(2), 308-322. https://doi.org/10.1287/orsc.1100.0543

Bendersky, C., \& Shah, N. P. (2013). The downfall of extraverts and rise of neurotics: The dynamic process of status allocation in task groups. Academy of Management Journal, 56(2), 387-406. https://doi.org/10.5465/amj.2011.0316

Berger, J., Webster Jr, M., Ridgeway, C. L., \& Rosenholtz, S. (1986). Status cues, expectations, and behavior. Advances in Group Processes, 3, 1-22.

Biesanz, J. C., Deeb-Sossa, N., Papadakis, A. A., Bollen, K. A., \& Curran, P. J. (2004). The role of coding time in estimating and interpreting growth curve models. Psychological Methods, 9(1), 30-54. https://doi.org/10.1037/1082-989X.9.1.30

Blau, P. M. (1977). Inequality and heterogeneity: A primitive theory of social structure (Vol 7). Free Press.

Bliese, P. D., \& Ployhart, R. E. (2002). Growth modeling using random coefficient models: 
Model building, testing, and illustrations. Organizational Research Methods, 5(4), 362-387. https://doi.org/10.1177/109442802237116

Boumgarden, P., Nickerson, J., \& Zenger, T. R. (2012). Sailing into the wind: Exploring the relationships among ambidexterity, vacillation, and organizational performance. Strategic Management Journal, 33(6), 587-610. https://doi.org/10.1002/smj.1972

Bunderson, J. S., \& Reagans, R. E. (2011). Power, status, and learning in organizations. Organization Science, 22(5), 1182-1194. https://doi.org/10.1287/orsc.1100.0590

Bunderson, J. S., \& Sanner, B. (2020). How and when can social hierarchy promote learning in groups? In L. Argote \& J. M. Levine (Eds.), Oxford handbook of group and organizational learning (1st ed., pp. 27-53). Oxford University Press, USA. https://doi.org/10.1093/oxfordhb/9780190263362.013.6

Bunderson, J. S., \& Van der Vegt, G. S. (2018). Diversity and inequality in management teams: A review and integration of research on vertical and horizontal member differences. Annual Review of Organizational Psychology and Organizational Behavior, 5(1), 47-73. https://doi.org/10.1146/annurev-orgpsych-032117-104500

Bunderson, J. S., Van der Vegt, G. S., Cantimur, Y., \& Rink, F. (2016). Different views of hierarchy and why they matter: Hierarchy as inequality or as cascading influence. Academy of Management Journal, 59(4), 1265-1289. https://doi.org/10.5465/amj.2014.0601

Bunderson, J. S., Van der Vegt, G. S., \& Sparrowe, R. T. (2014). Status inertia and member replacement in role-differentiated teams. Organization Science, 25(1), 57-72. https://doi.org/10.1287/orsc.2013.0835

Burke, M. J., Finkelstein, L. M., \& Dusig, M. S. (1999). On average deviation indices for estimating interrater agreement. Organizational Research Methods, 2(1), 49-68. 
https://doi.org/10.1177/109442819921004

Chase, I. D. (1980). Social process and hierarchy formation in small groups: A comparative perspective. American Sociological Review, 45(6), 905-924.

https://doi.org/10.2307/2094909

Chen, G. (2005). Newcomer adaptation in teams: Multilevel antecedents and outcomes. Academy of Management Journal, 48, 101-116. https://doi.org/10.5465/amj.2005.15993147

Chen, S., Lee-Chai, A. Y., \& Bargh, J. A. (2001). Relationship orientation as a moderator of the effects of social power. Journal of Personality and Social Psychology, 80(2), 173-187. https://doi.org/10.1037//0022-3514.S0.2.173

Chernick, M. R. (2011). Bootstrap methods: A guide for practitioners and researchers. John Wiley \& Sons.

Costa, P., \& McCrae, R. (1992). Revised NEO Personality Inventory (NEO PI-R) and NEO FiveFactor Inventory (NEO-FFI) Professional Manual. Psychological Assessment Resources.

De Dreu, C. K. W., Nijstad, B. A., Bechtoldt, M. N., \& Baas, M. (2011). Group creativity and innovation: A motivated information processing perspective. Psychology of Aesthetics, Creativity, and the Arts, 5(1), 81-97. https://doi.org/10.1037/a0017986

Demange, G. (2004). On group stability in hierarchies and networks. Journal of Political Economy, 112(4), 754-778. https://doi.org/10.1086/421171

Durham, C. C., Locke, E. A., Poon, J. M. L., \& McLeod, P. L. (2000). Effects of group goals and time pressure on group efficacy, information-seeking strategy, and performance. Human Performance, 13(2), 115-138. https://doi.org/10.1207/s15327043hup1302_1

Eisenhardt, K. M. (1989). Making fast strategic decisions in high-velocity environments. The Academy of Management Journal, 32(3), 543-576. https://doi.org/10.2307/256434 
Elliot, A. J., \& Thrash, T. M. (2002). Approach-avoidance motivation in personality: Approach and avoidance temperaments and goals. Journal of Personality and Social Psychology, 82(5), 804-818. https://doi.org/10.1037/0022-3514.82.5.804

Emerson, R. M. (1962). Power-dependence relations. American Sociological Review, 27(1), 3141. https://doi.org/10.2307/2089716

Evans, K., Sanner, B., \& Chiu, C.-Y. (Chad). (2021). Shared leadership, unshared burdens: How shared leadership structure schema lowers individual enjoyment without increasing performance. Group \& Organization Management, 1-46. https://doi.org/10.1177/1059601121997225

Fein, M. L. (2012). Human hierarchies: A general theory. Transaction Publishers.

Fiske, S. T., \& Berdahl, J. (2007). Social power. In A. W. Kruglanski \& E. T. Higgins (Eds.), Social psychology: Handbook of basic principles (pp. 678-692). Guilford Publications. https://doi.org/10.2307/2089716

Folkman, S. (1984). Personal control and stress and coping processes: A theoretical analysis. Journal of Personality and Social Psychology, 46(4), 839-852. https://doi.org/10.1037/0022-3514.46.4.839

Fragale, A. R. (2006). The power of powerless speech: The effects of speech style and task interdependence on status conferral. Organizational Behavior and Human Decision Processes, 101(2), 243-261. https://doi.org/10.1016/J.OBHDP.2006.01.004

French, J. R., \& Raven, B. (1959). The bases of social power. In D. Cartwright (Ed.), Studies in social power (pp. 151-167).

Gardner, H. K. (2012). Performance pressure as a double-edged sword. Administrative Science Quarterly, 57(1), 1-46. https://doi.org/10.1177/0001839212446454 
Gersick, C. J. . (1988). Time and transition in work teams: Toward a new model of group development. Academy of Management Journal, 31(1), 9-41. https://doi.org/10.2307/256496

Gersick, C. J. . (1989). Marking time: Predictable transitions in task groups. Academy of Management Journal, 32(2), 274-309. https://doi.org/10.5465/256363

Gersick, C. J. . (1994). Pacing strategic change: The case of a new venture. Academy of Management Journal, 37(1), 9-45. https://doi.org/10.5465/256768

Gersick, C. J. ., \& Hackman, J. R. (1990). Habitual routines in task-performing groups. Organizational Behavior and Human Decision Processes, 47(1), 65-97. https://doi.org/10.1016/0749-5978(90)90047-D

Grant, A. M., Gino, F., \& Hofmann, D. A. (2011). Reversing the extraverted leadership advantage: The role of employee proactivity. Academy of Management Journal, 54(3), 528550. https://doi.org/10.5465/AMJ.2011.61968043

Greer, L. L., de Jong, B. A., Schouten, M. E., \& Dannals, J. E. (2018). Why and when hierarchy impacts team effectiveness: A meta-analytic integration. Journal of Applied Psychology, 103(6), 591-613. https://doi.org/10.1037/ap10000291

Hage, J. (1995). Hierarchy. In N. Nicholson (Ed.), The Blackwell Encyclopedic Dictionary of Organizational Behavior (p. 122). Blackwell Publishers.

Halevy, N., Chou, E. Y., \& Galinsky, A. D. (2011). A functional model of hierarchy: Why, how, and when vertical differentiation enhances group performance. Organizational Psychology Review, 1(1), 32-52. https://doi.org/10.1177/2041386610380991

Halevy, N., Chou, E. Y., Galinsky, A. D., \& Murnighan, J. K. (2012). When hierarchy wins evidence from the National Basketball Association. Social Psychological and Personality 
Science, 3(4), 398-406. https://doi.org/10.1177/1948550611424225

He, J., \& Huang, Z. (2011). Board informal hierarchy and firm financial performance: Exploring a tacit structure guiding boardroom interactions. Academy of Management Journal, 54(6), 1119-1139. https://doi.org/10.5465/amj.2009.0824

Hinsz, V. B., Tindale, R. S., \& Vollrath, D. A. (1997). The emerging conceptualization of groups as information processors. Psychological Bulletin, 121(1), 43-64. https://doi.org/10.1037/0033-2909.121.1.43

Hoffman, L. R. (2015). Longitudinal analysis: Modeling within-person fluctuation and change. (New York). Routledge.

Hollenbeck, J. R., Ellis, A. P. J., Humphrey, S. E., Garza, A. S., \& Ilgen, D. R. (2011). Asymmetry in structural adaptation: The differential impact of centralizing versus decentralizing team decision-making structures. Organizational Behavior and Human Decision Processes, 114(1), 64-74. https://doi.org/10.1016/j.obhdp.2010.08.003

Humphrey, S. E., \& Aime, F. (2014). Team microdynamics: Toward an organizing approach to teamwork. Academy of Management Annals, 8(1), 443-503. https://doi.org/10.1080/19416520.2014.904140

Ilgen, D. R., Hollenbeck, J. R., Johnson, M., \& Jundt, D. (2005). Teams in organizations: From input-process-output models to IMOI models. Annual Review of Psychology, 56(1), 517543. https://doi.org/10.1146/annurev.psych.56.091103.070250

Johnson, M. D., Hollenbeck, J. R., Humphrey, S. E., Ilgen, D. R., Jundt, D., \& Meyer, C. J. (2006). Cutthroat cooperation: Asymmetrical adaptation to changes in team reward structures. Academy of Management Journal, 49(1), 103-119. https://doi.org/10.5465/amj.2006.20785533 
Johnson, M. D., Hollenbeck, J. R., Scott DeRue, D., Barnes, C. M., \& Jundt, D. (2013).

Functional versus dysfunctional team change: Problem diagnosis and structural feedback for self-managed teams. Organizational Behavior and Human Decision Processes, 122(1), 111. https://doi.org/10.1016/J.OBHDP.2013.03.006

Keltner, D., Van Kleef, G. A., Chen, S., \& Kraus, M. W. (2008). A reciprocal influence model of social power: Emerging principles and lines of inquiry. Advances in Experimental Social Psychology, 40, 151-192. https://doi.org/10.1016/S0065-2601(07)00003-2

Kennedy, D. M., \& Maynard, M. T. (2017). It is about time: Temporal considerations of team adaptation. In E. Salas \& W. B. Vessey (Eds.), Team dynamics over time (pp. 29-49). Emerald.

Kilduff, M., \& Lee, J. W. (2020). The integration of people and networks. Annual Review of Organizational Psychology and Organizational Behavior, 7(1), 155-179. https://doi.org/10.1146/annurev-orgpsych-012119-045357

Klein, K. J., Ziegert, J. C., Knight, A. P., \& Xiao, Y. (2006). Dynamic delegation: Shared, hierarchical, and deindividualized leadership in extreme action teams. Administrative Science Quarterly, 51(4), 590-621. https://doi.org/10.2189/asqu.51.4.590

Knight, A. P. (2015). Mood at the midpoint: Affect and change in exploratory search over time in teams that face a deadline. Organization Science, 26(1), 99-118. https://doi.org/10.1287/orsc.2013.0866

Krackhardt, D. (1994). Graph theoretical dimensions of informal organizations. In K. M. Carley \& M. J. Prietula (Eds.), Computational organizational theory (pp. 89-111). Lawrence Erlbaum.

Magee, J. C., \& Galinsky, A. D. (2008). Social hierarchy: The self-reinforcing nature of power 
and status. The Academy of Management Annals, 2(1), 351-398.

https://doi.org/10.1080/19416520802211628

Marks, M. A., Mathieu, J. E., \& Zaccaro, S. J. (2001). A temporally based framework and taxonomy of team processes. Academy of Management Review, 356-376. https://doi.org/10.5465/amr.2001.4845785

Martin, J. L. (2009). Formation and stabilization of vertical hierarchies among adolescents: Towards a quantitative ethology of dominance among humans. Social Psychology Quarterly, 72, 241-264. https://doi.org/10.1177/019027250907200307

Maynard, M. T., Kennedy, D. M., \& Sommer, S. A. (2015). Team adaptation: A fifteen-year synthesis (1998-2013) and framework for how this literature needs to "adapt" going forward. European Journal of Work and Organizational Psychology, 24(5), 652-677. https://doi.org/10.1080/1359432X.2014.1001376

McGrath, J. E. (1997). Small group research, that once and future field: An interpretation of the past with an eye to the future. Group Dynamics: Theory, Research, and Practice, 1(1), 727. https://doi.org/10.1037/1089-2699.1.1.7

Min, S. W., Humphrey, S. E., Aime, F., Petrenko, O. V., Quade, M. J., \& Fu, S. (2020). Dealing with new members: Team members' reactions to newcomer's attractiveness and sex. Journal of Applied Psychology, Online first. https://doi.org/10.1037/apl0000872

Mintzberg, H. (1979). The structuring of organizations: A synthesis of the research. University of Illinois at Urbana-Champaign's Academy for Entrepreneurial Leadership Historical Research Reference in Entrepreneurship.

Mitchell, T. R., \& James, L. R. (2001). Building better theory: Time and the specification of when things happen. Academy of Management Review, 26(4), 530-547. 
https://doi.org/10.5465/amr.2001.5393889

Moon, H., Hollenbeck, J., Humphrey, S., Illgen, D., West, B., Ellis, A. P., \& Porter, C. O. (2004). Asymmetric adaptability: Dynamic team structures as one-way streets. Academy of Management Journal, 47(5), 681-695. https://doi.org/10.5465/20159611

Morgeson, F. P., Mitchell, T. R., \& Liu, D. (2015). Event system theory: An event-oriented approach to the organizational sciences. Academy of Management Review, 40(4), 515-537. https://doi.org/10.5465/amr.2012.0099

Oedzes, J. J., Van der Vegt, G. S., Rink, F. A., \& Walter, F. (2019). On the origins of informal hierarchy: The interactive role of formal leadership and task complexity. Journal of Organizational Behavior, 40(3), 311-324. https://doi.org/10.1002/job.2330

Oh, S. H. D. (2012). Leadership emergence in autonomous work teams: Who is more willing to lead? Social Behavior and Personality, 40(9), 1451-1464. https://doi.org/10.2224/sbp.2012.40.9.1451

Park, S., Grosser, T. J., Roebuck, A. A., \& Mathieu, J. E. (2020). Understanding work teams from a network perspective: A review and future research directions. Journal of Management, 46(6), 1002-1028. https://doi.org/10.1177/0149206320901573

Qu, X., \& Liu, X. (2017). Informational faultlines, integrative capability, and team creativity. Group \& Organization Management, 42(6), 767-791. https://doi.org/10.1177/1059601117716008

Raudenbush, S. W., \& Bryk, A. S. (2002). Hierarchical linear models: Applications and data analysis methods. SAGE.

Sanner, B., \& Bunderson, J. S. (2018). The truth about hierarchy. MIT Sloan Management Review, 59(2), 48-52. 
Sanner, B., \& Evans, K. (2019). Deconstructing information elaboration: The critical role of framing and initial dialogue. Small Group Research, 50(4), 458-492. https://doi.org/org/10.1177/1046496419853019

Scott, C. P. R., Jiang, H., Wildman, J. L., \& Griffith, R. (2018). The impact of implicit collective leadership theories on the emergence and effectiveness of leadership networks in teams. Human Resource Management Review, 28(4), 464-481. https://doi.org/10.1016/j.hrmr.2017.03.005

Seers, A., \& Woodruff, S. (1997). Temporal pacing in task forces: Group development or deadline pressure? Journal of Management, 23(2), 169-187. https://doi.org/10.1177/014920639702300204

Singer, J. D., \& Willett, J. B. (2003). Applied longitudinal data analysis: Modeling change and event occurrence. Oxford University Press.

Strayer, F. F., \& Strayer, J. (1976). An ethological analysis of social agonism and dominance Relations among preschool children. Child Development, 47(4), 980. https://doi.org/10.2307/1128434

Summers, J. K., Humphrey, S. E., \& Ferris, G. R. (2012). Team member change, flux in coordination, and performance: Effects of strategic core roles, information transfer, and cognitive ability. Academy of Management Journal, 55(2), 314-338. https://doi.org/10.5465/amj.2010.0175

Thibaut, J. W., \& Kelley, H. H. (1956). The social psychology of groups. John Wiley \& Sons Inc.

Tiedens, L., Unzueta, M., \& Young, M. (2007). An unconscious desire for hierarchy? The motivated perception of dominance complementarity in task partners. Journal of 
Personality and Social Psychology, 93(3), 402-414. https://doi.org/10.1037/00223514.93.3.402

Torrance, E. P. (1954). The behavior of small groups under the stress conditions of "survival." American Sociological Review, 19(6), 751-755. https://doi.org/10.2307/2087922

Van der Vegt, G. S., \& Bunderson, J. S. (2005). Learning and performance in multidisciplinary teams: The importance of collective team identification. The Academy of Management Journal, 48(3), 532-547. https://doi.org/10.5465/AMJ.2005.17407918 


\section{Table 1}

\section{Correlations and Descriptive Statistics}

\begin{tabular}{|c|c|c|c|c|c|c|c|c|c|c|c|c|c|c|c|c|c|c|c|c|c|c|}
\hline & & Mean & $S D$ & 1 & 2 & 3 & 4 & 5 & 6 & 7 & 8 & 9 & 10 & 11 & 12 & 13 & 14 & 15 & 16 & 17 & 18 & 19 \\
\hline (1) & Team size & 4.38 & .59 & & & & & & & & & & & & & & & & & & & \\
\hline$(2)$ & Average age & 21.17 & 1.62 & -.07 & & & & & & & & & & & & & & & & & & \\
\hline (3) & Race diversity ${ }^{\mathrm{a}}$ & .28 & .24 & $.29 *$ & -.06 & & & & & & & & & & & & & & & & & \\
\hline (4) & Gender diversity ${ }^{\mathrm{a}}$ & .41 & .10 & -.17 & $-.29 *$ & -.12 & & & & & & & & & & & & & & & & \\
\hline$(5)$ & Average deference (T1) & 3.61 & .96 & $-.40 * *$ & .13 & -.10 & -.15 & & & & & & & & & & & & & & & \\
\hline (6) & Average deference (T2) & 4.39 & 1.01 & $-.28^{*}$ & .20 & -.07 & -.19 & $.67 * *$ & & & & & & & & & & & & & & \\
\hline (7) & Average deference (T3) & 4.47 & .81 & $-.26^{+}$ & $.25^{+}$ & .01 & -.06 & $.52 * *$ & $.77 * *$ & & & & & & & & & & & & & \\
\hline (8) & IH strength (T1) & .38 & .23 & -.22 & .12 & .02 & .03 & $.57 * *$ & $.38^{* *}$ & $.45^{* *}$ & & & & & & & & & & & & \\
\hline (9) & IH strength (T2) & .19 & .13 & $-.45 * *$ & $.27^{+}$ & $-.27 *$ & -.02 & .04 & -.09 & .06 & .12 & & & & & & & & & & & \\
\hline (10) & IH strength (T3) & .51 & .24 & -.08 & .00 & -.01 & -.18 & $.33^{*}$ & .15 & -.08 & .26 & .11 & & & & & & & & & & \\
\hline (11) & Pressure (T1) & 2.67 & .64 & $-.28^{*}$ & -.11 & -.20 & .00 & $.31 *$ & .22 & .08 & .13 & .13 & $.27 *$ & & & & & & & & & \\
\hline (12) & Pressure (T2) & 3.39 & .67 & -.07 & .24 & -.08 & $-.26^{+}$ & .08 & $.28^{*}$ & .24 & .00 & $.30 *$ & .14 & .24 & & & & & & & & \\
\hline (13) & Pressure (T3) & 3.28 & .81 & -.03 & .14 & -.14 & -.07 & .13 & -.17 & -.22 & -.03 & $.32 *$ & .21 & $.34 *$ & $.28^{*}$ & & & & & & & \\
\hline (14) & Extraversion (MI) & 4.70 & 1.24 & .01 & -.21 & .04 & .13 & .06 & .06 & .02 & -.04 & .05 & $.30 *$ & .21 & -.09 & .18 & & & & & & \\
\hline (15) & Neuroticism (MI) & 2.90 & .87 & -.18 & .13 & $-.34 *$ & .07 & $.27 *$ & .23 & $.30 *$ & .15 & .07 & $-.28 *$ & .01 & -.02 & -.10 & -.21 & & & & & \\
\hline (16) & Conscientiousness (MI) & 5.37 & .82 & -.02 & -.08 & .04 & -.01 & .14 & .01 & -.09 & .00 & -.11 & .16 & .03 & -.03 & .19 & -.03 & $-.25^{+}$ & & & & \\
\hline (17) & Agreeableness (MI) & 5.72 & .63 & .09 & $-.37 *$ & .03 & $.35^{*}$ & -.23 & $-.25^{+}$ & $-.32 *$ & -.15 & -.03 & .24 & -.08 & -.13 & .20 & $.34 *$ & $-.43 *$ & .22 & & & \\
\hline (18) & Openness (MI) & 4.88 & 1.05 & .00 & $-.26^{+}$ & -.21 & .20 & .10 & .08 & -.06 & .00 & .02 & -.03 & -.05 & .01 & $-.24^{+}$ & .19 & $.27 *$ & .13 & .15 & & \\
\hline (19) & $\begin{array}{l}\text { IH strength change after } \\
\text { the midpoint }\end{array}$ & .49 & .04 & .00 & .02 & -.05 & -.13 & -.17 & -.21 & $-.32 *$ & -.01 & $.36^{* *}$ & $.84 * *$ & .15 & .18 & .23 & $.29 *$ & $-.44 * *$ & .07 & $.37 * *$ & -.09 & \\
\hline (20) & Team performance & 86.65 & 15.41 & -.18 & -.16 & $-.29 *$ & .08 & .27 & $.29 *$ & .23 & .08 & -.10 & -.14 & .18 & -.06 & $-.26^{+}$ & .13 & .20 & $-.29 *$ & -.19 & .14 & $-.29 *$ \\
\hline
\end{tabular}

Notes: $\mathrm{N}=55$ teams

$\mathrm{T} 1$ = early project phase, $\mathrm{T} 2=$ midpoint, $\mathrm{T} 3=$ late project phase; $\mathrm{MI}=$ Most influential member at the midpoint; $\mathrm{IH}=\mathrm{Informal}$ hierarchy ameasured by Blau's (1977) index

$+\mathrm{p}<.10 ; * p<.05 ; * * p<.01$ 


\section{Table 2}

Results of HLM Regression Models Predicting Informal Hierarchy Strength

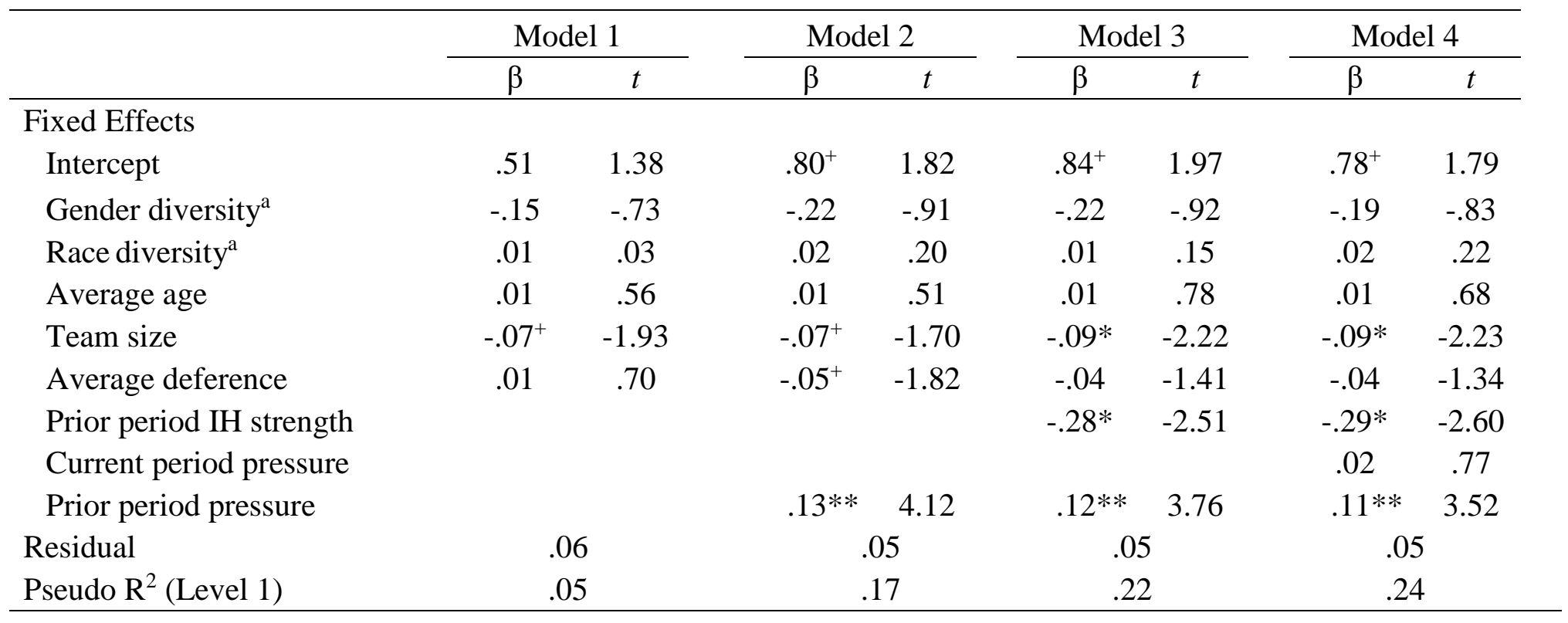

Notes: $\mathrm{N}=110$ observations in 55 teams

$\mathrm{IH}=$ Informal hierarchy

${ }^{a}$ measured by Blau's (1977) index

${ }^{+} p<.10 ; * p<.05 ; * * p<.01$ 


\section{Table 3}

Results of Growth Models Testing Change in Informal Hierarchy Strength over Time

\begin{tabular}{lcccc}
\hline & \multicolumn{2}{c}{ Model 1 } & \multicolumn{2}{c}{ Model 2} \\
\hline Fixed effects & $.38^{* *}$ & $(.03)$ & .47 & $(.42)$ \\
$\quad$ Intercept & $-.45^{* *}$ & $(.07)$ & $-.47^{* *}$ & $(.07)$ \\
Time & $.26^{* *}$ & $(.04)$ & $.26^{* *}$ & $(.03)$ \\
Time & & & -.10 & $(.21)$ \\
Gender diversity $^{\mathrm{a}}$ & & & .01 & $(.08)$ \\
Race diversity & & & .01 & $(.01)$ \\
Average age & & & $-.07 *$ & $(.03)$ \\
Team size & & & .02 & $(.02)$ \\
$\quad$ Average deference & & & & \\
Random effects & & & .09 & $(.04)$ \\
$\quad$ Intercept & .11 & $(.04)$ & .07 & $(.03)$ \\
Time & .07 & $(.02)$ & & \\
$\quad$ Intercept-time correlation & -.53 & $(.40)$ & -.47 & $(.48)$ \\
Residual & .18 & $(.02)$ & .18 & $(.01)$ \\
Log likelihood & 21.04 & & 13.65 \\
Akaike information criterion & \multicolumn{2}{c}{-28.10} & & -3.30 \\
\hline
\end{tabular}

Notes: $\mathrm{N}=165$ observations nested in 55 teams. Time is coded such that the intercept represents the informal hierarchy strength at the start of the project life (i.e. $\mathrm{T} 1=0, \mathrm{~T} 2=1, \mathrm{~T} 3=2$ ). Bootstrap standard errors are in parentheses.

${ }^{a}$ measured by Blau's (1977) index.

$+\mathrm{p}<.10 ; * \mathrm{p}<.05 ; * * \mathrm{p}<.01$ 


\section{Table 4}

Results of Growth Models Testing Effects of Most Influential Person on Change in Informal Hierarchy Strength

\begin{tabular}{|c|c|c|c|c|c|c|c|c|c|c|c|c|}
\hline \multirow{2}{*}{ Fixed effects } & \multicolumn{2}{|c|}{ Model 1} & \multicolumn{2}{|c|}{ Model 2} & \multicolumn{2}{|c|}{ Model 3} & \multicolumn{2}{|c|}{ Model 4} & \multicolumn{2}{|c|}{ Model 5} & \multicolumn{2}{|c|}{ Model 6} \\
\hline & & & & & & & & & & & & \\
\hline Intercept & $.50 * *$ & $(.03)$ & .47 & $(.42)$ & $.56^{*}$ & $(.28)$ & $.57 *$ & $(.28)$ & $.58 *$ & $(.28)$ & $.59 *$ & $(.26)$ \\
\hline Time & $.58 * *$ & $(.06)$ & $-.47 * *$ & $(.07)$ & $.60 * *$ & $(.06)$ & $.60 * *$ & $(.06)$ & $.60 * *$ & $(.06)$ & $.60 * *$ & $(.06)$ \\
\hline Time $^{2}$ & $.26 * *$ & $(.03)$ & $.26 * *$ & $(.03)$ & $.28 * *$ & $(.03)$ & $.28 * *$ & $(.03)$ & $.28 * *$ & $(.03)$ & $.28 * *$ & $(.03)$ \\
\hline Gender diversity $^{\mathrm{a}}$ & & & -.10 & $(.21)$ & -.18 & $(.15)$ & -.18 & $(.15)$ & -.19 & $(.16)$ & -.19 & $(.16)$ \\
\hline Race diversity ${ }^{\mathrm{a}}$ & & & .01 & $(.08)$ & .03 & $(.06)$ & .03 & $(.06)$ & .03 & $(.06)$ & .03 & $(.06)$ \\
\hline Average age & & & .01 & $(.01)$ & -.00 & $(.01)$ & -.00 & $(.01)$ & -.00 & $(.01)$ & -.00 & $(.01)$ \\
\hline Team size & & & $-.07 *$ & $(.03)$ & $-.05^{+}$ & $(.03)$ & $-.05^{+}$ & $(.03)$ & $-.05^{+}$ & $(.03)$ & $-.05^{+}$ & $(.03)$ \\
\hline Average deference & & & .02 & $(.02)$ & $.06^{* *}$ & $(.02)$ & $.05 * *$ & $(.02)$ & $.05 * *$ & $(.02)$ & $.05 * *$ & $(.02)$ \\
\hline Conscientiousness (MI) & & & & & .01 & $(.02)$ & .00 & $(.02)$ & .00 & $(.02)$ & .00 & $(.02)$ \\
\hline Agreeableness (MI) & & & & & .03 & $(.03)$ & .03 & $(.03)$ & .03 & $(.03)$ & .03 & $(.03)$ \\
\hline Openness (MI) & & & & & -.00 & $(.02)$ & -.00 & $(.02)$ & -.00 & $(.02)$ & -.00 & $(.02)$ \\
\hline Extraversion (MI) & & & & & .01 & $(.01)$ & $.04 *$ & $(.02)$ & .01 & $(.01)$ & $.04^{+}$ & $(.02)$ \\
\hline Neuroticism (MI) & & & & & -.01 & $(.02)$ & -.01 & $(.02)$ & $-.08 *$ & $(.03)$ & $-.06 *$ & $(.03)$ \\
\hline Time $\mathrm{x}$ Extraversion (MI) & & & & & & & $.03 *$ & $(.01)$ & & & $.03^{+}$ & $(.01)$ \\
\hline Time x Neuroticism (MI) & & & & & & & & & $-.06 *$ & $(.02)$ & $-.05 *$ & $(.02)$ \\
\hline \multicolumn{13}{|l|}{ Random effects } \\
\hline Intercept & .12 & $(.03)$ & .09 & $(.04)$ & .10 & $(.04)$ & .09 & $(.04)$ & .08 & $(.04)$ & .07 & $(.03)$ \\
\hline Time & .07 & $(.03)$ & .07 & $(.03)$ & .08 & $(.03)$ & .07 & $(.03)$ & .06 & $(.03)$ & .05 & $(.03)$ \\
\hline Intercept-time correlation & .66 & $(.49)$ & -.47 & $(.48)$ & .98 & $(.06)$ & .99 & $(.23)$ & .99 & $(.24)$ & .99 & $(.46)$ \\
\hline Residual & .18 & $(.02)$ & .18 & $(.01)$ & .17 & $(.01)$ & .17 & $(.01)$ & .17 & $(.01)$ & .17 & $(.01)$ \\
\hline Log likelihood & \multicolumn{2}{|c|}{21.04} & \multicolumn{2}{|c|}{13.65} & \multicolumn{2}{|c|}{46.0} & \multicolumn{2}{|c|}{48.2} & \multicolumn{2}{|c|}{49.3} & \multicolumn{2}{|c|}{50.8} \\
\hline $\begin{array}{l}\text { Akaike information } \\
\text { criterion }\end{array}$ & \multicolumn{2}{|c|}{-28.10} & \multicolumn{2}{|c|}{-3.30} & \multicolumn{2}{|c|}{-58.0} & \multicolumn{2}{|c|}{-60.5} & \multicolumn{2}{|c|}{-62.6} & \multicolumn{2}{|c|}{-63.5} \\
\hline
\end{tabular}

Notes: $\mathrm{N}=156$ observations nested in 52 teams. Time is coded such that the intercept represents the change in hierarchy late in project life (i.e.

$\mathrm{T} 1=-2, \mathrm{~T} 2=-1, \mathrm{~T} 3=0) .{ }^{a}$ measured by Blau's (1977) index. Bootstrap standard errors are in parentheses. MI $=$ Most influential member at the midpoint; $+\mathrm{p}<.10 ; * \mathrm{p}<.05 ; * * \mathrm{p}<.01$ 
Table 5

Results of OLS Regression Models Predicting Team Performance

\begin{tabular}{|c|c|c|c|c|}
\hline & \multicolumn{2}{|c|}{ Model 1} & \multicolumn{2}{|c|}{ Model 2} \\
\hline & $\mathrm{B}$ & $t$ & $\mathrm{~B}$ & $t$ \\
\hline Intercept & $114.71 * *$ & 2.83 & $197.59 * *$ & 3.53 \\
\hline Gender diversity $^{\mathrm{a}}$ & 4.37 & .20 & -2.37 & -.11 \\
\hline Race diversity ${ }^{\mathrm{a}}$ & $-16.80^{+}$ & -1.96 & $-17.48 *$ & -2.11 \\
\hline Team size & -.07 & -.02 & -.92 & -.24 \\
\hline Average age & -1.91 & -1.47 & -1.95 & -1.55 \\
\hline Average deference & $4.31^{+}$ & 1.85 & $5.47 *$ & 2.35 \\
\hline IH strength change after the midpoint & & & $-162.71 *$ & -2.07 \\
\hline$F$ & \multicolumn{2}{|c|}{2.18} & \multicolumn{2}{|c|}{2.65} \\
\hline Degrees of freedom & \multicolumn{2}{|c|}{5,49} & \multicolumn{2}{|c|}{6,48} \\
\hline Adjusted $R^{2}$ & \multicolumn{2}{|c|}{$.07^{+}$} & \multicolumn{2}{|c|}{$.16^{*}$} \\
\hline
\end{tabular}

Notes: $\mathrm{N}=55$ teams.

$\mathrm{IH}=$ Informal hierarchy

${ }^{a}$ measured by Blau's (1977) index

${ }^{+} p<.10 ; * p<.05 ; * * p<.01$ 


\section{Figure 1}

Illustrations of the Strengthening and Weakening of Informal Hierarchy

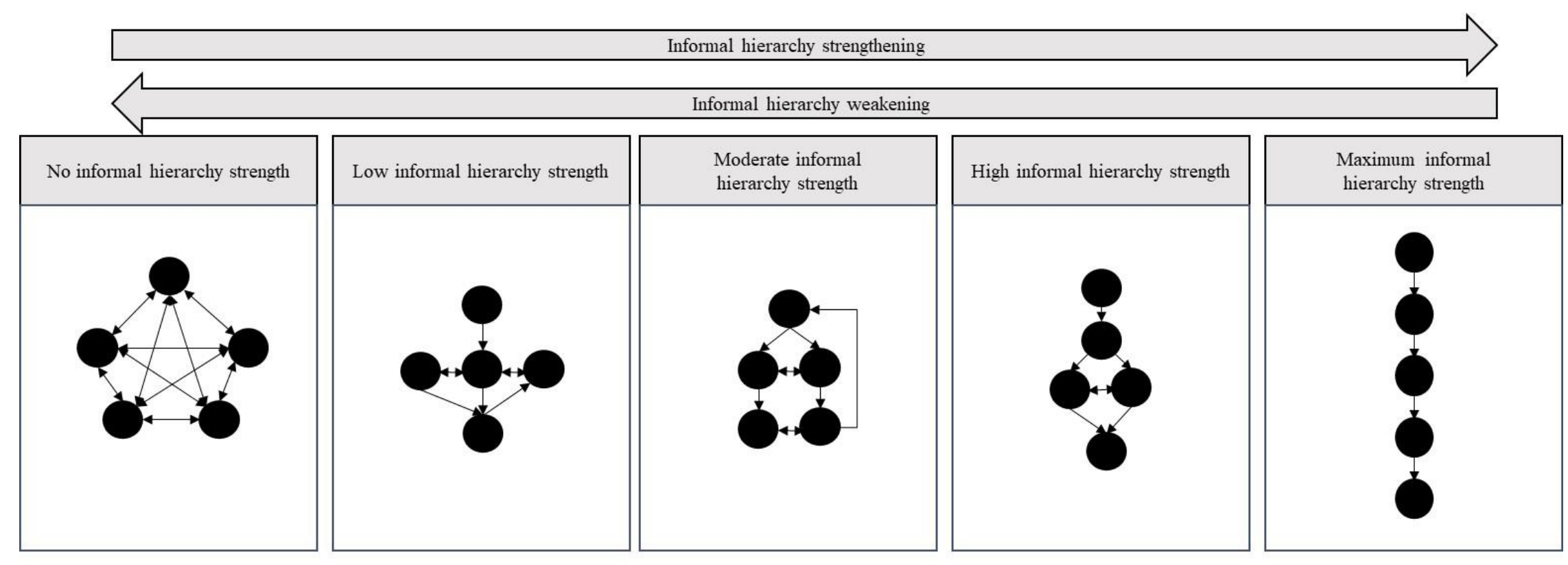

Note. Circles represent members and arrows represent the directional flow of influence between members. 


\section{Figure 2}

Illustrative Model of Informal Hierarchy Strength Changes

Self-managed project team phases

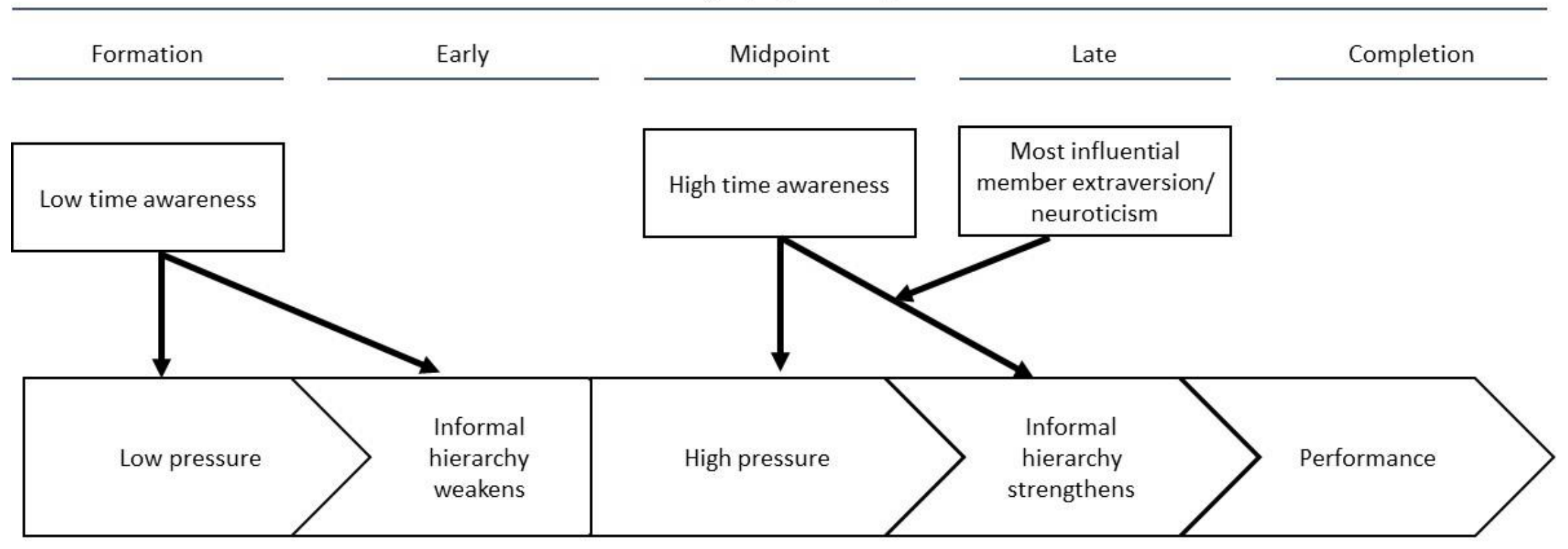




\section{Figure 3}

Curvilinear Relationship between Time and Informal Hierarchy Strength

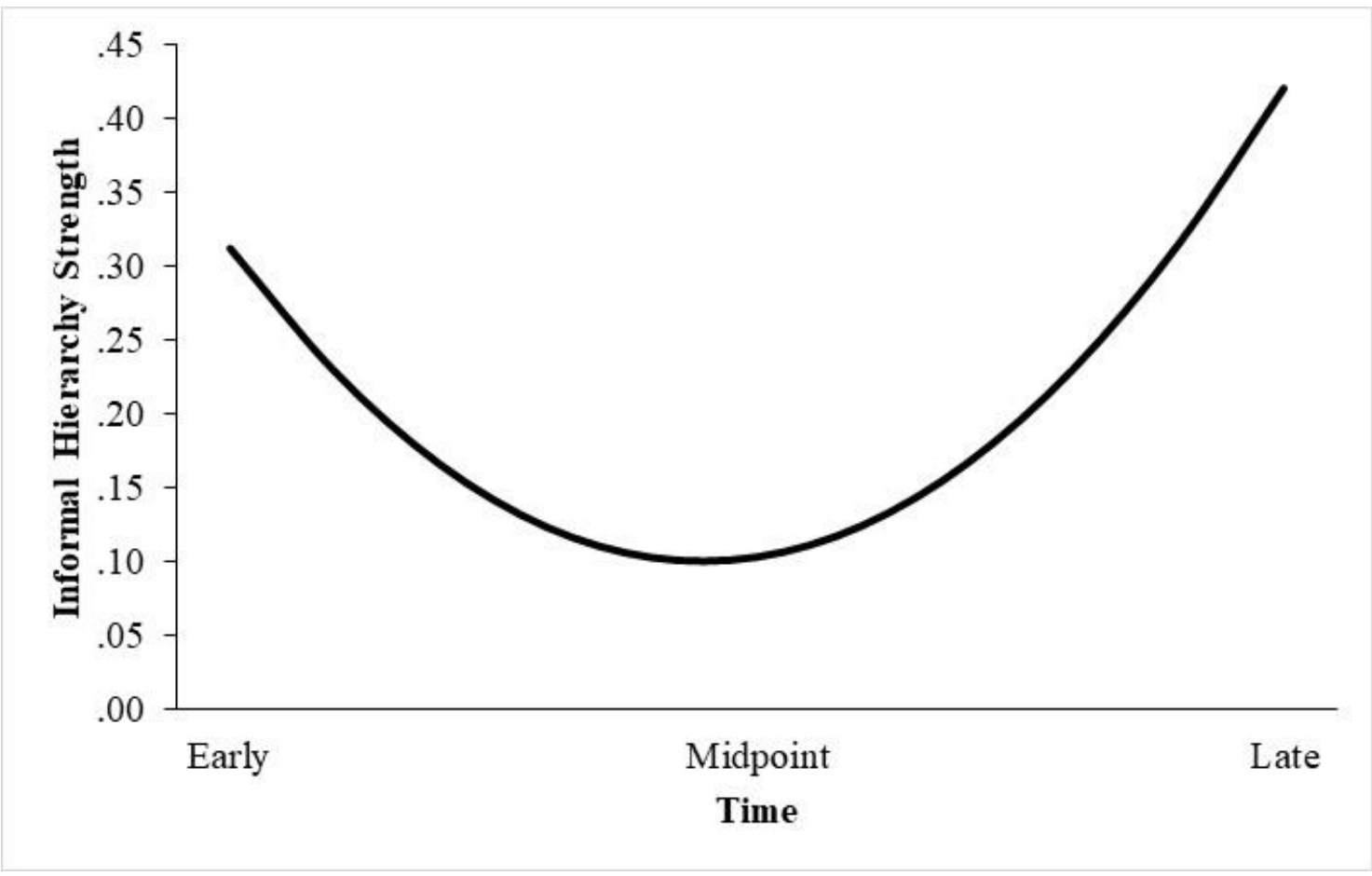




\section{Figure 4}

Linear Growth of Informal Hierarchy Strength Late in Project Life by Extraversion of Most Influential Member

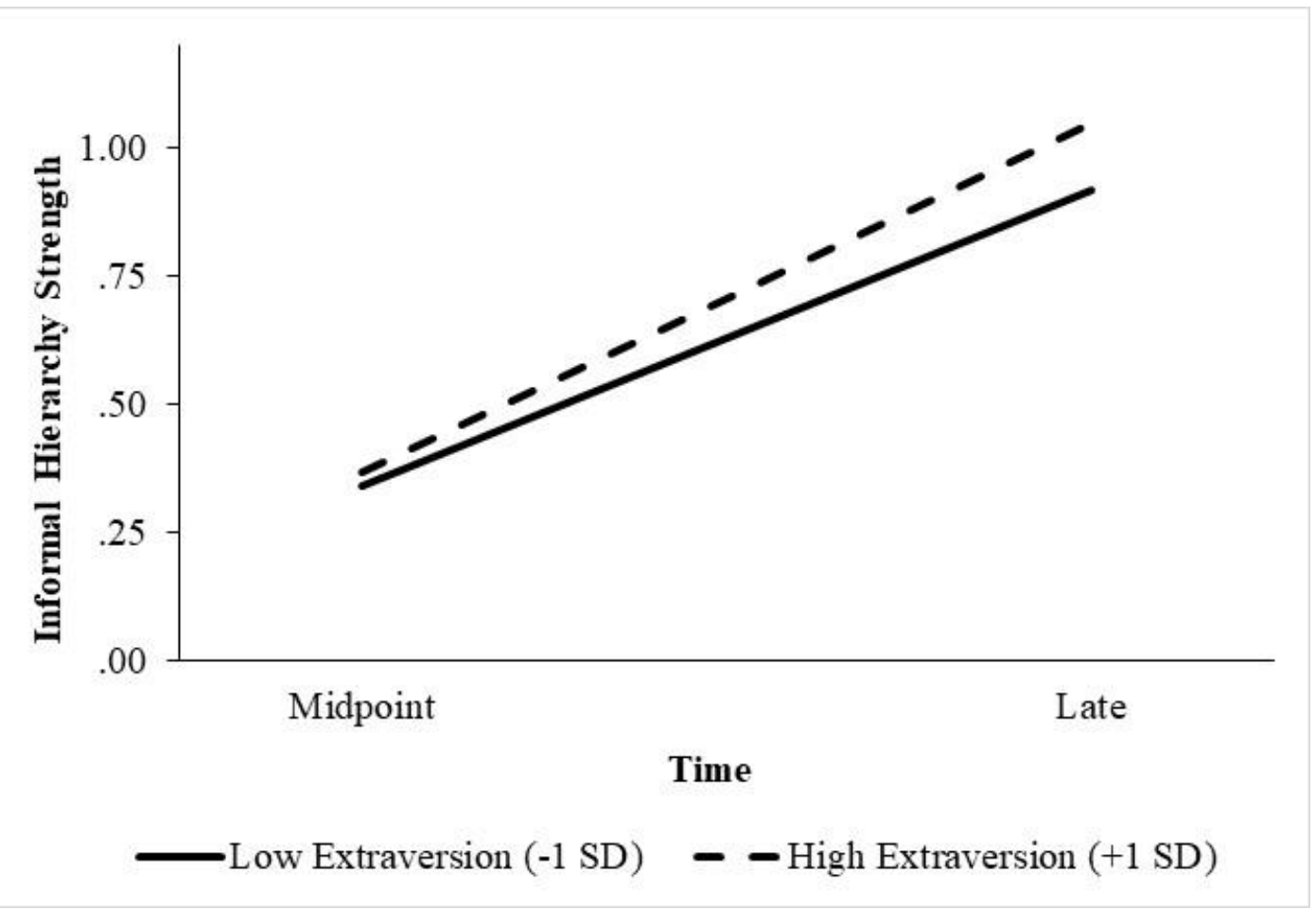




\section{Figure 5}

Linear Growth of Informal Hierarchy Strength Late in Project Life by Neuroticism of Most Influential Member

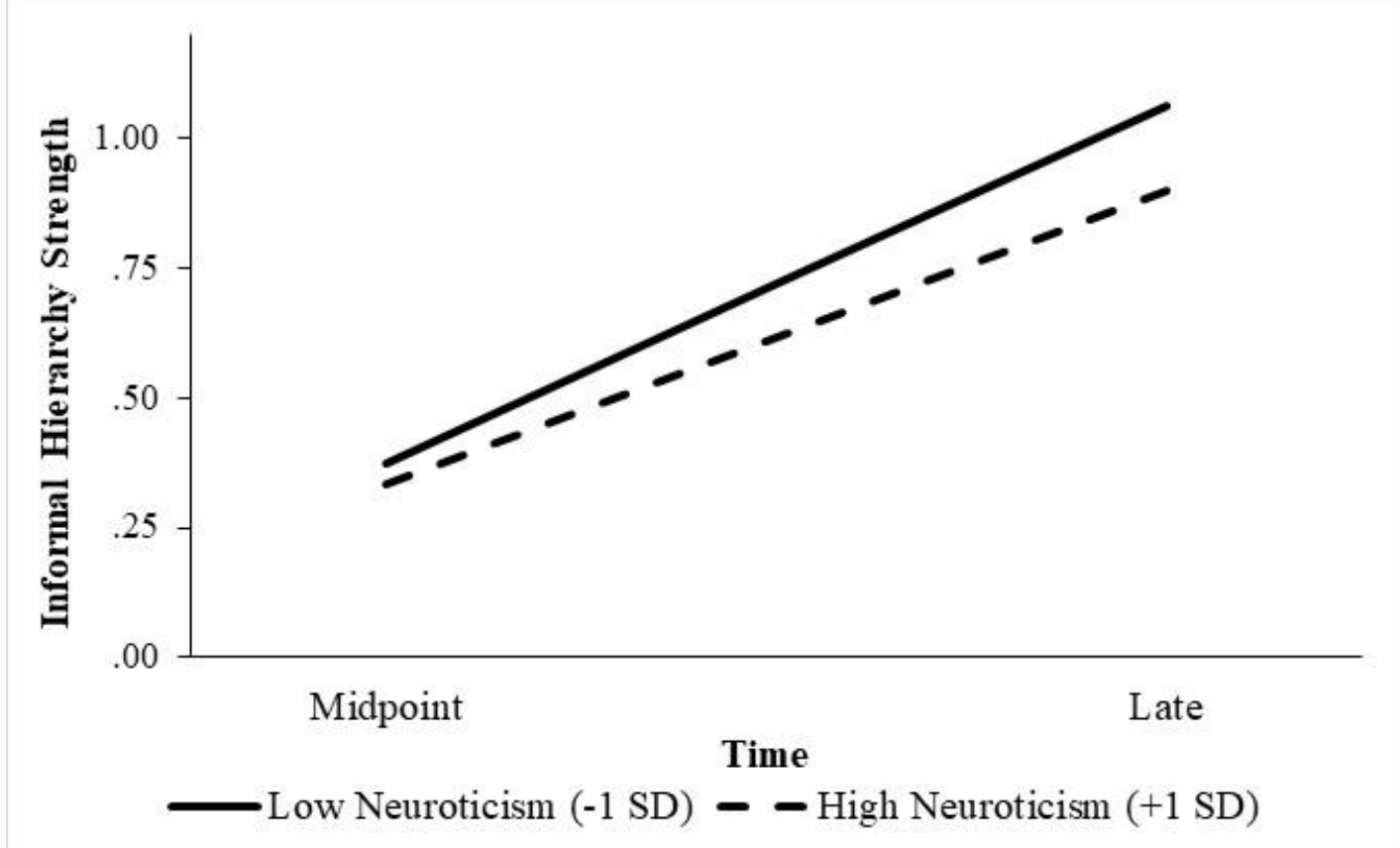




\section{Appendix}

Overview of Published Empirical Research on Informal Hierarchy Strength

\begin{tabular}{|c|c|c|c|c|c|c|}
\hline Paper & $\begin{array}{c}\text { Primary } \\
\text { theoretical } \\
\text { lens }{ }^{1}\end{array}$ & $\begin{array}{c}\text { \# of } \\
\text { times IH } \\
\text { strength } \\
\text { measured }\end{array}$ & Input & Mediator & Moderator & DV \\
\hline $\begin{array}{l}\text { Bunderson et } \\
\text { al., } 2016\end{array}$ & Functionalist & 1 & $\begin{array}{l}\text { Informal hierarchy } \\
\text { strength }\end{array}$ & $\begin{array}{l}\text { Process } \\
\text { conflict }\end{array}$ & Complexity & $\begin{array}{c}\text { Performance/ member } \\
\text { satisfaction }\end{array}$ \\
\hline $\begin{array}{l}\text { He \& Huang, } \\
2011\end{array}$ & Functionalist & 1 & $\begin{array}{l}\text { Informal hierarchy } \\
\text { strength }\end{array}$ & & $\begin{array}{l}\text { CEO being highest on } \\
\text { informal hierarchy/ directors } \\
\text { have medium ranks/ board } \\
\text { size/ past performance/ } \\
\text { dynamic industry }\end{array}$ & $\begin{array}{l}\text { Firm financial } \\
\text { performance }\end{array}$ \\
\hline $\begin{array}{l}\text { Oedzes, et al., } \\
2018\end{array}$ & MIP-G & 1 & $\begin{array}{l}\text { Informal hierarchy } \\
\text { strength }\end{array}$ & & Empowering leadership & Creativity \\
\hline $\begin{array}{l}\text { Oedzes, et al., } \\
2019\end{array}$ & Functionalist & 1 & $\begin{array}{l}\text { Formal leader and } \\
\text { directive leadership }\end{array}$ & & Task complexity & $\begin{array}{l}\text { Informal hierarchy } \\
\text { strength }\end{array}$ \\
\hline $\begin{array}{l}\text { Ronay et al., } \\
2012\end{array}$ & Functionalist & 1 & $\begin{array}{l}\text { Informal hierarchy } \\
\text { strength }\end{array}$ & Conflict & Interdependence & Productivity \\
\hline
\end{tabular}

${ }^{1}$ Functionalist: views informal hierarchy strength as benefiting teams by facilitating progress (Bunderson et al., 2016; Halevy et al., 2011; Magee \& Galinsky, 2008); MIP-G: Motivated Information Processing in Groups (De Dreu et al., 2011; Hinsz et al., 1997) implies that informal hierarchy strength's outcomes depends on the extent to which it motivates teams to share information. IH $=$ Informal hierarchy 